This item was submitted to Loughborough's Research Repository by the author.

Items in Figshare are protected by copyright, with all rights reserved, unless otherwise indicated.

\title{
Lignocellulosic bioethanol production: Prospects of emerging membrane technologies to improve the process - A critical review
}

PLEASE CITE THE PUBLISHED VERSION

https://doi.org/10.1515/revce-2018-0014

\section{PUBLISHER}

(C) De Gruyter

\section{VERSION}

VoR (Version of Record)

\section{PUBLISHER STATEMENT}

This paper was published in the journal Reviews in Chemical Engineering and is available at https://doi.org/10.1515/revce-2018-0014.

\section{LICENCE}

CC BY-NC-ND 4.0

\section{REPOSITORY RECORD}

Dey, Pinaki, Parimal Pal, Joseph Dilip Kevin, and Diganta Das. 2018. "Lignocellulosic Bioethanol Production: Prospects of Emerging Membrane Technologies to Improve the Process - A Critical Review". Loughborough University. https://hdl.handle.net/2134/36249. 
Pinaki Dey*, Parimal Pal, Joseph Dilip Kevin and Diganta Bhusan Das

\section{Lignocellulosic bioethanol production: prospects of emerging membrane technologies to improve the process - a critical review}

https://doi.org/10.1515/revce-2018-0014

Received March 22, 2018; accepted July 13, 2018

Abstract: To meet the worldwide rapid growth of industrialization and population, the demand for the production of bioethanol as an alternative green biofuel is gaining significant prominence. The bioethanol production process is still considered one of the largest energy-consuming processes and is challenging due to the limited effectiveness of conventional pretreatment processes, saccharification processes, and extreme use of electricity in common fermentation and purification processes. Thus, it became necessary to improve the bioethanol production process through reduced energy requirements. Membrane-based separation technologies have already gained attention due to their reduced energy requirements, investment in lower labor costs, lower space requirements, and wide flexibility in operations. For the selective conversion of biomasses to bioethanol, membrane bioreactors are specifically well suited. Advanced membrane-integrated processes can effectively contribute to different stages of bioethanol production processes, including enzymatic saccharification, concentrating feed solutions for fermentation, improving pretreatment processes, and finally purification processes. Advanced membrane-integrated simultaneous saccharification, filtration, and fermentation strategies consisting of ultrafiltration-based enzyme recycle system with nanofiltration-based high-density cell recycle fermentation system or the combination of highdensity cell recycle fermentation system with membrane pervaporation or distillation can definitely contribute to the development of the most efficient and economically

*Corresponding author: Pinaki Dey, Department of Biotechnology, Karunya Institute of Technology and Sciences, Karunya Nagar Coimbatore 641114, India, e-mail: saspinaki@gmail.com

Parimal Pal: Department of Chemical Engineering, National Institute of Technology, Durgapur, India

Joseph Dilip Kevin: Department of Biotechnology, Karunya Institute of Technology and Sciences, Coimbatore, India

Diganta Bhusan Das: Department of Chemical Engineering, School of AACME, Loughborough University, Loughborough, Leicestershire, UK sustainable second-generation bioethanol production process.

Keywords: bioethanol; conventional processes; lignocelluloses; membrane-integrated process; SSFF.

\section{Introduction}

Due to the increasing energy crisis and growing environmental concerns, there has been an emergent need for alternative renewable fuel sources to replace fossil fuelbased conventional energy sources. Among all potential alternative fuels, bioethanol in the form of biofuel derived from biomass can well contribute to the mitigation of greenhouse gas emissions and can provide clean environment. Therefore, there has been a paradigm shift in the business strategies of chemical industries throughout the world toward the production of such high demanding green biofuel employing energy-efficient technologies. According to the agreement implemented by the Policy Energy Act and the Energy Independence and Security Act, the predicted target to produce bioethanol in the form of green fuel was fixed at 36 billion gallons by year 2022 (Limayem and Ricke 2012). A target to produce biofuel about 60 billion gallons per year by 2030 was made by the US Department of Energy to fulfill the future demands of transportation fuel (Himmel et al. 2007). To meet such huge demands, governments of all developed nations have been involved in identifying suitable feedstock and developing most advanced technology for sustainable biofuel production. Based on the food versus fuel controversy, the research focus has been shifted to implementing inedible biowaste materials such as lignocellulosic biomass as renewable feedstock for biofuel production. The utilization of such promising, low-cost lignocellulosic biomass in the form of municipal, industrial, and agricultural wastes has been encouraged for the large-scale production of biofuel (Cardona and Sánchez 2007). However, the recalcitrant nature of lignocellulosic feedstock makes the overall process intensive toward high labor and capital investment (Himmel et al. 2007). Even most of the conventional steps involved in lignocellulosic bioethanol 
production process have their own limitations. The major disadvantages of existing pretreatment processes of lignocellulosic biomass include high cost involvements, high power and energy consumption, chances of equipment corrosion, formation of inhibitory compounds, and solvents are required to recycled; due to those limitations, the large-scale application of those common pretreatment processes is still under investigation (Aditiya et al. 2016). Similarly, conventional saccharification and fermentation processes are generally considered time-consuming as both processes are carried out separately, considered expensive due to high enzyme loading options, and finally come up with lower yield of fermentable sugar and ethanol as both processes suffer from product inhibition problem. The most common limitations of the conventional distillation process include its energy-consuming nature and inefficiency to separate components from mixture in some cases. Thus, it became an emergent need to improve all existing conventional processing strategies of lignocellulosic bioethanol production, including conventional pretreatment, hydrolysis, fermentation, and purification with advanced energy-efficient technologies.

Due to the advantages of reduced energy requirements, lower labor costs, lower space requirements, and wide range of operational flexibility, membrane-based technologies gained more and more attention to replace conventional energy-intensive technologies (Chapman et al. 2008, Pal and Dey 2013). The selective and efficient transport properties of specific compounds made the membrane technology applicable and acceptable for a wide range of applications specifically from filtration process of industrial waste water engineering to membrane bioreactor (MBR)-based production oriented processes (Mutamim et al. 2013). In second-generation lignocellulosic bioethanol production, the most important application of membrane technology resides in the purification and concentration of prehydrolyzates, enzymatic saccharification process, cell recycle fermentation process, and product recovery process. For that, the judicious selection, combination, and integration among microfiltration (MF), ultrafiltration (UF), and nanofiltration (NF) processes have been formulated by different researchers to make the overall process continuous, compact, and successful. The most widely used carbon sources for membrane reactor-based bioethanol production process have been pure and expensive carbohydrate sources such as glucose, fructose, sucrose, and lactose (Cheryan and Mehaia 1983, Hoffmann et al. 1985, Melzoch et al. 1991, Ding et al. 2012) and industrial wastes such as whey, molasses, and sludge-based materials (Mehaia and Cheryan 1990, Tin and Mawson
1993, Kaseno and Kokugan 1997, Lee and Yeom 2007). Such waste substrates demanded time and expensive pretreatment strategies to avoid membrane fouling. To control over membrane fouling, several membrane modules such as hollow-fiber, tubular, and cross-flow modules have been investigated (Mehaia and Cheryan 1990, Melzoch et al. 1991), although it is a well known fact that only cross-flow membrane modules can offer long hours of fouling free operation (Dey and Pal 2012). Concentration polarization is another common problem that can influence membrane performance during high solid loading saccharification process and comes up with enzyme activity loss, although such difficulty can be controlled by adopting optimized hydrolysis reaction rate by selecting a suitable dilution rate of substrate (Andrić et al. 2010). Existing experimental studies of membrane reactor systems for lignocellulosic bioethanol production mainly focused on the utilization of abundant agricultural lignocellulosic waste substances such as rice straw and wheat straw (Ishola et al. 2013, 2015a,b, Ylitervo et al. 2014, Zahed et al. 2016), but still now many more promising lignocellulosic substrates such as kans grass and coconut mesocarp are overlooked by researchers in the field of membrane-based lignocellulosic bioethanol production.

Among all existing studies of membrane technologybased bioethanol production process, Ishola et al. (2013) only reported the advanced concept of the simultaneous saccharification, filtration, and fermentation (SSFF) scheme for bioethanol production from spruce chipsbased substrate. In the next study (Ishola et al. 2015a), the same method was implemented with wheat straw substrate to produce bioethanol. In both studies, the advantages of the SSFF process with respect to separate hydrolysis and fermentation (SHF) and simultaneous saccharification and fermentation (SSF) processes were highlighted, but none of these existing studies implemented the most useful membrane properties to increase simple sugar concentration before fermentation to improve the concentration and productivity of bioethanol. In our proposed MBR scheme, a two-stage membrane-integrated bioreactor system (SSFF) configuring the UF membrane separation process in the first stage for the enzymatic saccharification process followed by the NF-based cell recycle high cell density fermentation system has been represented in cross-flow mode with prior increase in sugar concentration in the bioreactor. A judicious combination of high-density cell recycle fermentation system with membrane pervaporation or membrane distillation unit in the final stage can also come up with the high purity of the product. 
This review specifically focused on the recent developments of existing processes and their bottlenecks that interfere with lignocellulosic biofuel production specifically in the commercial level. This review also highlighted possible solutions to those existing challenges through the adaptation of advanced membrane technologies. Efficient membrane processes that may effectively contribute to the improvements of existing biorefinery processes are clearly addressed in this paper. It transpires from the tireless efforts of early researchers on membrane-based bioethanol production schemes. We have identified a better and novel scheme of a compact, flexible, and less energy-intensive membrane plant through this comprehensive review.

\section{Existing processes of ligno- cellulosic bioethanol production}

In the last three decades, lignocellulosic substrates that are comparatively abundant in nature have been mainly used for the production of second-generation biofuel (AlZuhair et al. 2013). It is even more preferred and advantageous than microalgae-based biofuel production as such third-generation biofuel is comparatively less stable, production will not continue for a long time, and extraction of such fuel is comparatively difficult and costly (BiofuelsThird Generation Biofuels, 2010). The conventional transformation of lignocellulosic biomass to bioethanol can be accomplished by two different approaches (i.e. biochemical and thermochemical processes). Both routes involve the destruction of the crystalline structure of lignocelluloses by the maximum removal of lignin and separation of hemicellulosic and cellulosic materials. Such polysaccharide (hemicellulose and cellulose) materials can be further hydrolyzed to sugars that can be converted to bioethanol with subsequent production strategies. Considering the involvement of comparatively environment-friendly and economic nature (Limayem and Ricke 2012) of the techniques, biochemical processes are preferred more in the conversion of lignocellulosic bioethanol. The upstream operation of such biochemical pathway involves (a) the pretreatment processes of biomass to reduce its recalcitrant structure and to increase the accessibility of enzyme on it, (b) the enzymatic or acidic hydrolysis of hemicellulosic materials to produce monomeric simple sugars, and (c) the subsequent fermentative conversion of such simple sugars to bioethanol (Sánchez and Cardona 2008, Limayem and Ricke 2012). Distillation is the conventional downstream process used for the separation and purification of bioethanol.

\subsection{Pretreatment processes}

Pretreatment is the fundamental strategy to reduce the recalcitrance nature of lignocellulosic material to facilitate the enzymatic action on plant polysaccharides. The main purpose of pretreatment is to solubilize and separate one or more of the structural components, namely, hemicellulose, lignin, and cellulose, from biomass. Thus, the process increases substrate porosity with lignin redistribution and permits the maximum exposure of saccharification enzymes to cellulose and hemicellulose surfaces to achieve improved hydrolysis with minimal energy consumption (Zhu and Pan 2010). In the last few decades, several approaches have been evolved as economic and most useful pretreatment processes for lignocellulosic biomass. Pretreatment processes are broadly classified in four different groups, namely, (a) physical pretreatment, (b) chemical pretreatment, (c) physicochemical pretreatment, and (d) biological pretreatment. Different classifications of all these existing pretreatment methodologies are represented in Figure 1.

Under physical pretreatment, mechanical comminution is considered as the most common technique where, through the combination of chipping, grinding, and milling, lignocellulosic materials can be comminuted from 10 to $30 \mathrm{~mm}$ to 0.2 to $2 \mathrm{~mm}$ (Kumar et al. 2009, Balat 2011). Milling methods, specifically ball milling, tworoll milling, hammer milling, colloid milling, and vibroenergy milling, can play a significant role in reducing the particle size and degree of crystallinity (Taherzadeh and Karimi 2008) and improving the digestibility (Kumar et al. 2009) of lignocellulosic biomass. Energy consumption in mechanical comminution is totally dependent on the type of material used during the process and particle size required after pretreatment. Balat (2011) clearly reported that the energy consumption to reduce the particle size of $1.6 \mathrm{~mm}$ for hardwood material was $130 \mathrm{kWh} / \mathrm{ton}$, and it was $14 \mathrm{kWh} /$ ton for the same particle size reduction of corn stover. The specific energy consumption was reported to reduce the particle size of wheat straw material to 0.8 and $3.2 \mathrm{~mm}$ through hammer mill, which were 51.6 and $11.4 \mathrm{kWh} /$ ton (Talebnia et al. 2010). Pyrolysis is another endothermic physical pretreatment process, which is well known for less energy consumption (Sarkar et al. 2012). In this method, the cellulosic material rapidly decomposes to gaseous products such as $\mathrm{H}_{2}$, $\mathrm{CO}$, and residual char through the exposure of temperature greater than $300^{\circ} \mathrm{C}$. The residual char is further processed by leaching to get enough carbon sources such as glucose to support microbial growth (Sarkar et al. 2012). Leustean (2009) clearly pointed out that pyrolysis pretreatment was effective to 


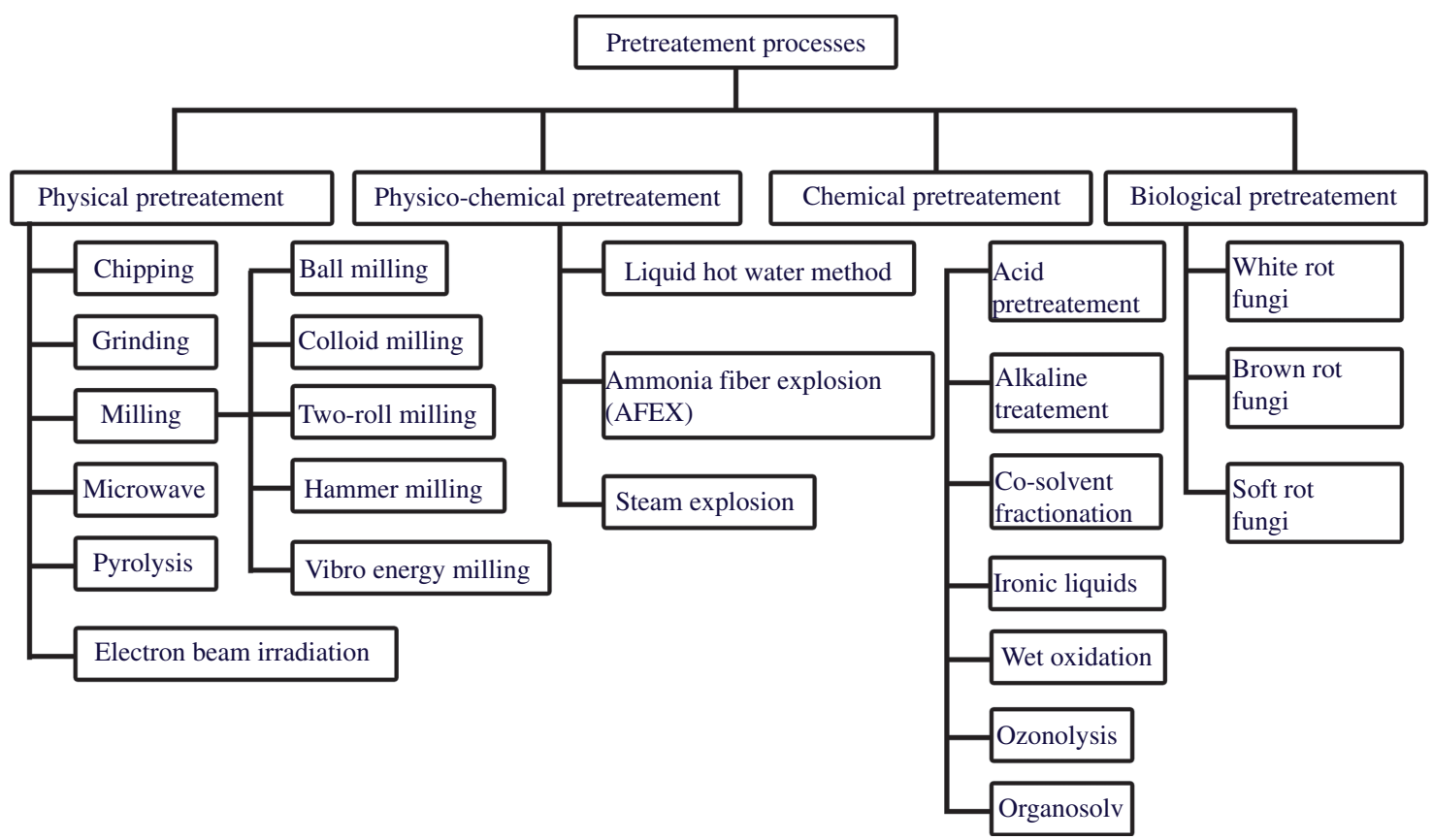

Figure 1: Classifications of different pretreatment methodologies to reduce the recalcitrant nature and crystallinity of lignocellulosic biomass.

achieve improved conversion of cellulosic material from ground material to glucose. Microwave and electronbeam irradiation are also feasible physical pretreatment approaches that are easy to operate (Bjerre et al. 2000). Microwave pretreatment uses high heating efficiency of a microwave oven whereas electron-beam irradiation is aligned with continuously changing magnetic field (Sarkar et al. 2012). Irradiation basically helps in other pretreatment processes as it cannot separate hemicellulose or lignin directly from lignocellulosic materials (Sun et al. 2016). Duarte et al. (2012) highlighted that electron beam or $\gamma$-rays combined with mechanical crushing can further enhance the enzymatic saccharification process of lignocellulosic biomass. High-energy radiations of $\gamma$-rays with deeper penetration power is successful in improving the digestibility of enzymes (Jahnavi et al. 2017). Highenergy requirement and the expensive nature of such treatments hinders their applicability in industrial applications (Taherzadeh and Karimi 2008).

Alkaline pretreatment is regarded as the most commonly used chemical pretreatment method to digest lignin matrix and make cellulose and hemicellulose available for enzymatic degradation. A variety of alkaline reagents such as sodium hydroxide $(\mathrm{NaOH}), \mathrm{Ca}(\mathrm{OH})_{2}, \mathrm{KOH}$, $\mathrm{Na}_{2} \mathrm{CO}_{3}$, and aqueous ammonia have been implemented for different lignocellulosic materials, and among them $\mathrm{NaOH}, \mathrm{Ca}(\mathrm{OH})_{2}$ is generally used in most of the cases
(Sun et al. 2016). The cell wall of lignocellulosic materials is normally disrupted by solubilizing hemicelluloses, lignin, and silica and the crystallinity of cellulose is finally reduced due to swelling (Sarkar et al. 2012). It helps the substrates to be fractionated into alkali-soluble lignin, hemicelluloses, and residues. The advantages of alkaline pretreatment includes ambient operating conditions and the utilization of lower temperature and pressure than other treatment procedures (Mosier et al. 2005, Balat 2011). Cai and Zhang (2005) pointed out the efficiency of alkaline $\mathrm{NaOH} /$ urea solutions in dissolving, swelling, and fragmenting cellulose material at low temperature (about $-15^{\circ} \mathrm{C}$ ). Sun et al. (2016) suggested that low temperature at $\mathrm{NaOH}$ treatment leads to high accessibility of lignocellulosic material in saccharification stages by increasing the swelling of that material. The effectiveness of $\mathrm{NaOH}$ in increasing the digestibility of hardwood material from $14 \%$ to $55 \%$ and reduction of lignin content up to $55 \%$ was shown by Kumar et al. (2009). Sun et al. (1995) evaluated the most effecting $\mathrm{NaOH}$ concentration of $1.5 \%$ for separation of $60 \%$ lignin and $80 \%$ hemicellulose from wheat straw material when the material was treated at $20^{\circ} \mathrm{C}$ for $144 \mathrm{~h}$. NaOH pretreatment was effective enough to retain the lignin content to even less than $26 \%$ for hardwood, wheat straw, switch grass, and softwood materials (Zhao et al. 2008). Less than 65\% reduction of lignin from cotton stalk material was similarly reported 
by Silverstein et al. (2007) when the material was treated with $2 \% \mathrm{NaOH}$ for $90 \mathrm{~min}$ at $121^{\circ} \mathrm{C}$ and 15 psi. Utilization of $\mathrm{NaOH}$ pretreatment and its combination with other pretreatment processes in the reduction of lignin and increasing accessibility of cellulose from kans grass material was demonstrated by Ashgar et al. (2016), Chaudhary et al. (2012), and Kataria and Ghosh (2014). The maximum loss of solid including lignin of $47.5 \%$ was reported by Kataria and Ghosh (2014), whereas total lignin removal of $40 \%$ and $74 \%$ were reported by Ashgar et al. (2016) and Chaudhary et al. (2012), respectively, during $\mathrm{NaOH}$ pretreatment. Ammonia pretreatment is also considered as noncorrosive and nontoxic alkaline treatment (Kim et al. 2016). Compared to $\mathrm{NaOH}$ pretreatment, lime $\left(\mathrm{Ca}(\mathrm{OH})_{2}\right)$ treatment is another efficient method that leads to increase the crystallinity index with the removal of lignin involving lower cost, less safety requirements, and better environmental benefits (Alvira et al. 2010, Balat 2011). Kim and Holtzapple (2005) reported that removal of $43.6 \%-48.4 \%$ original lignin was possible from corn stover-based lignocellulosic material by nonoxidative lime pretreatment, whereas lignin removal was $57.8 \%-87.5 \%$ from oxidative lime pretreatment at $25^{\circ} \mathrm{C}-55^{\circ} \mathrm{C}$ for 16 weeks.

Among all other chemical pretreatments, acid pretreatment is considered effective to achieve directly high yield of sugars from lignocellulosic materials. Even acid pretreatment is also applied to solubilize fractional hemicelluloses from lignocellulosic material; hence, it has been preferably used in the process of fractionating components of lignocellulosic biomass (Sun et al. 2016). The acids that are studied in such purposes are hydrochloric acid ( $\mathrm{HCl})$, sulfuric acid $\left(\mathrm{H}_{2} \mathrm{SO}_{4}\right)$, phosphoric acid $\left(\mathrm{H}_{3} \mathrm{PO}_{4}\right)$, and nitric acid ( $\mathrm{HNO}_{3}$; Menon and Rao 2012). Operating conditions that are followed for acid treatments are (a) high temperature and low acid concentration and (b) low temperature and high acid concentration. For a large array of biomasses such as switch grass, corn stover, spruce, poplar, kans grass, coconut fiber, and rice/wheat straw, $\mathrm{H}_{2} \mathrm{SO}_{4}$ has been commonly implemented in diluted conditions (Zhu et al. 2008, Wyman et al. 2009, Digman et al. 2010). However, the biggest drawback of acid treatment is the production of various microbial growth inhibitors such as acetic acid, furfural, and 5-hydroxymethyalfurfural, which are needed to be detoxified before fermentation. Generally, higher recovery of xylose and enhanced enzymatic digestibility can be achieved with higher pretreatment temperature and short residence time. Diluted $\mathrm{H}_{2} \mathrm{SO}_{4}$ concentration of $(0.2-2 \%)$ and higher temperature $\left(121-372^{\circ} \mathrm{C}\right)$ were implemented in all existing studies in the same research field as it facilitates most important functions such as hydrolysis of hemicellulose, exposure of cellulose for digestion, and solubilization of heavy metals (Balat 2011). Hernández et al. (2013) demonstrated the maximum recovery of cellulose up to $87 \%$ and xylan up to $50.2 \%$ from empty pods of Moringa oleifera at diluted $\mathrm{H}_{2} \mathrm{SO}_{4}$ treatment. Saha et al. (2005) achieved $74 \%$ yield in saccharification process of wheat straw material when it was treated with $0.75 \%(\mathrm{v} / \mathrm{v})$ volume of $\mathrm{H}_{2} \mathrm{SO}_{4}$ at $121^{\circ} \mathrm{C}$ for $1 \mathrm{~h}$. Solid acid catalyst utilization in the pretreatment process is another emerging technique that leads to better saccharification efficiency. In a saccharification study of macroalgae cellulosic material (Tan and Lee 2015), optimum yield of glucose was enhanced to $99.8 \%$ through soiled acid pretreatment technique $[10 \%(\mathrm{w} / \mathrm{v})$ biomass loading, $4 \%(\mathrm{w} / \mathrm{v})$ catalyst loading, $\left.30 \mathrm{~min}, 120^{\circ} \mathrm{C}\right]$ followed by enzymatic hydrolysis. In another experimental observation, Qi et al. (2018) developed carbon-based solid $\left(\mathrm{C}-\mathrm{SO}_{3} \mathrm{H}\right)$ acid catalyst by carbonization technique using microcrystalline cellulose and $\mathrm{H}_{2} \mathrm{SO}_{4}$. Such solid catalyst showed high catalytic activity during pretreatment of corncob-based lignocellulosic substrate and the initial xylose recovery yield was achieved $78.1 \%$.

Recently, ionic liquids as green solvent consisting large organic cations and small inorganic anions are gaining importance for the pretreatment of lignocellulosic biomass. Mainly two classes of ionic liquids (simple salts and binary ionic liquids) have been implemented as powerful solvents to dissolve cellulose or lignocellulosic biomass (Menon and Rao 2012). Li et al. (2010) investigated the effect of phosphate and chloride group of ionic liquids in the pretreatment studies of corncob. For sugarcane bagasse, twofold higher enzymatic hydrolysis yield was observed when it was pretreated with 1,3-N-methylmorpholine-N-oxide ionic liquids (Kuo and Lee 2009). In a similar study (Saha et al. 2017a), better pretreatment of sugarcane bagasse was obtained with ionic liquid 1-ethyl3-methylimidazolium acetate at the ratio of 1:20 (w/w) at $140^{\circ} \mathrm{C}$ for $120 \mathrm{~min}$. Xu et al. (2015) pointed out that pretreatment for $24 \mathrm{~h}$ with similar ionic liquid 1-ethyl-3-methyl-imidazolium dimethylphosphate was effective to solubilize more than $40 \%$ lignin. Zhao et al. (2009) clearly indicated that lignocellulosic material pretreated with ionic liquids always shows much lower crystallinity and higher accessibility of enzymes than untreated biomass. Dadi et al. (2006) highlighted ionic pretreatment with Avicel-PH-101 was useful to increase the enzymatic hydrolysis rate and yield up to $50 \%$ and twofold, respectively, in comparison to the untreated one. Jahnavi et al. (2017) indicated the presence of four major groups of cations in ionic liquids to categorize ionic liquid. Menon and Rao (2012) clearly explained different aspects including advantages, disadvantages, and challenges of using ionic liquids in 
different pretreatment case studies. Some techniques such as ozonolysis, organosolv, wet oxidation, cosolvent fractionation, and $\gamma$-valerolactone have been newly emerged as potential chemical pretreatment process, but still the industrial feasibility of such processes will be dependent on their technoeconomic suitability for large-scale operations. Among all such mentioned techniques, oraganosolv (utilization of organic solvent and/or aqueous solvent) is a promising alternative method for the delignification of lignocellulosic material. The utilization of methanol, ethanol, acetone, ethyl glycol, and tetrahydrofurfural alcohol allows the isolation and recovery of pure lignin (Jahnavi et al. 2017). The processes are normally carried out between $150^{\circ} \mathrm{C}$ and $200^{\circ} \mathrm{C}$ to break hemicellulose bonds and such processes became efficient when they are combined with acid catalysts (Alvira et al. 2010).

Steam explosion, which is known as autohydrolysis, is the most promising method under physicochemical pretreatment. Lignocellulosic materials are subjected to high-pressure saturated steam $(0.69-4.83 \mathrm{MPa})$ and temperature $\left(160-260^{\circ} \mathrm{C}\right)$ for a short period of time like to several seconds to minutes and then suddenly the pressure is reduced to atmospheric pressure. Pan et al. (2005) pointed out that hemicelluloses and lignin materials can be released through stream pretreatment followed by $\mathrm{NaOH}$ treatment. Horn et al. (2011) showed that steamtreated $\left(170-220^{\circ} \mathrm{C}\right)$ wheat straw sample became efficient during enzymatic hydrolysis. Residence time, temperature, biomass size, and moisture content are the most influencing parameters in such process (Jedvert et al. 2012). Due to some attractive features such as low environmental influence, utilization of less harsh chemicals, and high-energy efficiency, steam explosion has now been widely used before lignocellulosic hydrolysis (Alvira et al. 2010). The main drawback of this process is the production of inhibiting aromatic compounds or byproducts, which are required to be detoxified through vigorous water washing or other methods. Boussaid et al. (2000) indicated that both enzymatic digestion and recovery of total sugars have been improved with medium steam explosion technique. Addition of acids such as $\mathrm{H}_{2} \mathrm{SO}_{4}$ at low concentration or $0.3 \%-3 \% \mathrm{CO}_{2}$ improves the overall process by reducing temperature, increasing hydrolysis rate, and lowering the production of inhibitory compounds by the complete removal of hemicelluloses (Bondesson et al. 2013). Martín et al. (2002) explored the same advantage of the process with sugarcane bagasse material when it was impregnated with $\mathrm{SO}_{2}$ and $\mathrm{H}_{2} \mathrm{SO}_{4}$ before steam explosion at $205^{\circ} \mathrm{C}$ for $10 \mathrm{~min}$. In this study, higher yield of xylose was obtained from $\mathrm{SO}_{2}$ impregnated sugarcane bagasse, whereas higher yield of glucose was achieved from $\mathrm{H}_{2} \mathrm{SO}_{4}$ impregnated sugarcane bagasse. Tomás-Pejó et al. (2008) observed that wheat straw became a useful substrate for SSF-based bioethanol production after steam explosion treatment at $200^{\circ} \mathrm{C}$ for $10 \mathrm{~min}$.

Ammonia fiber explosion (AFEX) is another physicochemical pretreatment method which exposes lignocellulosic material to liquid ammonia at relatively moderate temperature of $90^{\circ} \mathrm{C}-100^{\circ} \mathrm{C}$ and at high pressure of $250-$ $300 \mathrm{psi}$ for 30-60 min (Kim et al. 2011). The salient feature of this process is the partial decrystallization of cellulose and the fractionation of lignin is caused by the swelling action of liquid ammonia. Although AFEX pretreatment method is effective to remove little lignin and hemicellulose from lignocellulosic material, it does not produce any inhibitors and the processing time is comparatively less. Parameters such as ammonia loading, temperature, water loading, blow down pressure, number of treatments, and time determine the efficiency of the process. The main drawback of such process is that it is less efficient for biomass containing higher lignin such as softwood newspaper (Sun and Cheng 2002). Alizadeh et al. (2005) achieved 93\% glucan conversion from switch grass pretreated with liquid ammonia near $100^{\circ} \mathrm{C}$ for $5 \mathrm{~min}$. Similarly Teymouri et al. (2005) achieved approximately $100 \%$ conversion of cellulose and $80 \%$ conversion of hemicellulose to fermentable sugars when corn stover was pretreated with AFEX at $90^{\circ} \mathrm{C}$ for 5 min followed by enzymatic hydrolysis. Harun et al. (2013) recovered 97\% ammonia and it was reused for the subsequent batches of AFEX pretreatment with rice straw as substrate.

Under physicochemical pretreatment, liquid hot water (LHW) method is another useful strategy to hydrolyze the maximum amount of hemicellulose (Das Neves et al. 2007). The temperature normally maintained in this hydrothermal process is between $170^{\circ} \mathrm{C}$ and $230^{\circ} \mathrm{C}$ and at the pressure above $5 \mathrm{MPa}$ for $20 \mathrm{~min}$. Water acts as acid at higher temperature; therefore, it facilities the maximum hydrolysis of hemicellulose into liquid phase and the maximum recovery of xylose (88-98\%) can be achieved without any other chemical treatment. Although the process is regarded as environmentally and economically attractive, it still suffers from the production of microbial growth-inhibiting compounds such furfural and carboxylic acid. In an experimental investigation of LHW with bamboo, Xiao et al. (2014) observed the maximum removal of hemicelluloses and less degradation of cellulose after different stages of pretreatment in temperature range of $140^{\circ} \mathrm{C}-200^{\circ} \mathrm{C}$ for $10-120 \mathrm{~min}$. Yu et al. (2009) achieved the maximum xylose recovery of $86.4 \%$ through two-stage LHW treatment of Eucalyptus grandis. Zhuang et al. (2016) evaluated the comparative effectiveness of LHW process 
in lowering downstream pressure to increase the accessibility of cellulose. Lu et al. (2013) observed that LHW treatment at $180^{\circ} \mathrm{C}-210^{\circ} \mathrm{C}$ for 20 min was useful for fed-batch SSF process for bioethanol production from reed-based substrate.

Among all such pretreatment processes, biological pretreatment is considered as the most environmentfriendly process as degradation of lignocellulosic complexes is carried out in mild conditions with the help of microorganisms such as brown rot, white rot, and soft rot fungi. Among such fungi, white rod fungi such as Phanerochaete chrysosporium, Ceriporia lacerata, Cyathus stercoreus, Ceriporiopsis subvermispora, Pycnoporus cinnabarinus, and Pleurotus ostreatus have been used successfully in the pretreatment process of different lignocellulosic biomass (Hatakka 1983, Prasad et al. 2007). Enzymes such as laccase, lignin peroxidase, and manganese peroxidases can play the most vital role in such pretreatment process by modifying lignin content (Floudas et al. 2012). Although the process has many advantages including less energy requirement, utilization of no added chemicals, and mild condition for treatment, long pretreatment time impedes its industrial application (Sun et al. 2016). Suhara et al. (2012) achieved high lignin degradation ( $>50 \%)$ from bamboo culms after 12 weeks of pretreatment using white rot basidiomycete Punctularia sp. In another study of biological pretreatment, Singh et al. (2008) achieved delignification efficiency of $60 \%-92 \%$ from fungus Trichoderma reesei and Aspergillus terreus. Canam et al. (2011) highlighted the potential of genetically modified microorganism such as the cellobiose dehydrogenase-deficient Trametes versicolor strain for such pretreatment studies.

A lot of research efforts have been focused for the successful conversion of lignocellulosic biomass to its valuable constituents through the development of effective pretreatment strategy. But still, obstacles in the existing pretreatment processes make the overall lignocellulosic bioethanol production commercially challenging. It includes the insufficient separation of cellulose and lignin, formation of byproducts that inhibit ethanol fermentation, high use of chemicals or energy, and considerable generation of wastes (Menon and Rao 2012). The conventional method of acid pretreatment with concentration below $4 \%$ and temperature greater than $160^{\circ} \mathrm{C}$ comes up with the formation of toxic inhibitors such as furfural from xylose and hydrothermal furfural (HMF) from glucose in addition to acidic acids and phenolics (Taherzadeh 1999). Separation and detoxification of acetic acid with concentration greater than $10 \mathrm{~g} / \mathrm{l}$ is more difficult than furfural and HMF. Therefore, the estimation of inhibitory toxic levels is the major concern for evaluating the cost-effectiveness of pretreatment processes. Parameters such as toxic inhibitors formed per level of sugar recovered and ratio of energy consumption versus sugar yield mostly determines the overall cost-effectiveness of the process (Zhu and Pan 2010). Several pretreatment methods, including mechanical, chemical, or biological methods, have been evolved for reducing the recalcitrant nature of the cell wall, although some of them still remain economically unfeasible due to key technical issues. The efficient pretreatment process for one particular feedstock may not be suitable for another biomass. Biological pretreatment necessities, careful control of slow microbial growth conditions, and a large amount of space are required to carry out the treatment processes, and most of the lignolytic microorganisms solubilize cellulose and hemicellulose along with lignin (Eggeman and Elander 2005). As a result, the treatment became less attractive in a commercial standpoint. Only few pretreatment processes including steam explosion, LHW, and AFEX have been reported for technoeconomic analysis. As membrane processes permit the permeability of the selective components, it can play the most effective role for the separation of cellulose, hemicellulose, lignin, and inhibitory components from pretreated mixture. Hence, membrane-integrated treatment opportunities after immediate pretreatment stages will definitely helpful improve the overall process economics.

\subsection{Hydrolysis method}

Chemical hydrolysis and enzymatic hydrolysis are two most commonly applied methods used for the conversion of simple sugars from lignocellulosic materials before fermentation. Other hydrolysis methods including $\gamma$-rays or electron-beam irradiation or microwave irradiation can be implemented for such conversions, but the assessment of economic suitability for such processes is more important before industrial applications (Balat 2011).

Under chemical hydrolysis, diluted acid hydrolysis and concentrated acid hydrolysis are two conventional techniques where lignocellulosic materials are exposed to diluted acid or concentrated acid for a specific period of time and specific temperature for the conversion of simple sugars. Diluted acid hydrolysis is comparatively more advantageous as it facilitates the step-by-step hydrolysis for the separation of hemicellulose and cellulose compounds, whereas concentrated acid (70-90\%) hydrolysis mainly facilitates the liberation of hemicellulosic sugars (Hayes 2009). Minimum sugar degradation and achieving maximum sugar yield up to $100 \%$ are the most positive 
features of such process, although the high cost of acid consumption and environmental and corrosion problems make the process unsuitable for commercial applications.

Enzymatic hydrolysis comes up with $100 \%$ selective conversion of hemicellulosic materials to simple sugars with fewer requirements of energy and mild environmental conditions (Ferreira et al. 2009). The recalcitrance nature of lignocellulosic materials due to the presence of lignin, high surface area, and cellulose crystallinity makes the enzymatic hydrolysis very slow (Pan et al. 2006). Mild environmental conditions (temperature $\left.40-50^{\circ} \mathrm{C}, \mathrm{pH} 4-5\right)$, less corrosion properties, high yield (75-85\%) of reactions, and selective operations make the enzymatic hydrolysis more suitable than acid hydrolysis (Hamelinck et al. 2005). Enzymatic hydrolysis is substrate specific, as cellulase enzymes break down bonds of cellulose molecules and hemicellulase enzymes are only responsible for hemicellulose molecules. Cellulases are group of enzymes that synergistically hydrolyze cellulose to glucose monomers. Such enzymatic mechanism is carried out by endoglucanases, exoglucanases, or cellobiohydrolases and $\beta$-glucoside enzymes. Endoglucanase hydrolyzes intramolecular $\beta$-1,4-glucosidic bonds of cellulose chains randomly to produce new chain ends, whereas exoglucanases suitably cleave cellulose chains at the ends to release soluble cellobiose or glucose and $\beta$-glucosides hydrolyze cellobiose to glucose. Hemicellulases are the complex mixture of at least eight enzymes that hydrolyze hemicellulose to xylose and arbinose as five-carbon sugars and galactose, glucose, and mannose as six-carbon sugars. The generalized process for the pretreatment of lignocellulosic biomass to remove lignin and further enzymatic saccharification process to produce simple sugars is represented in Figure 2. A wide range of fungi and bacteria such as Trichoderma, Penicillium, Fusarium, Phanerochaete, Humicola, Schizophyllum, Aspergillus, and Bacillus spp. have been successfully reported for cellulase

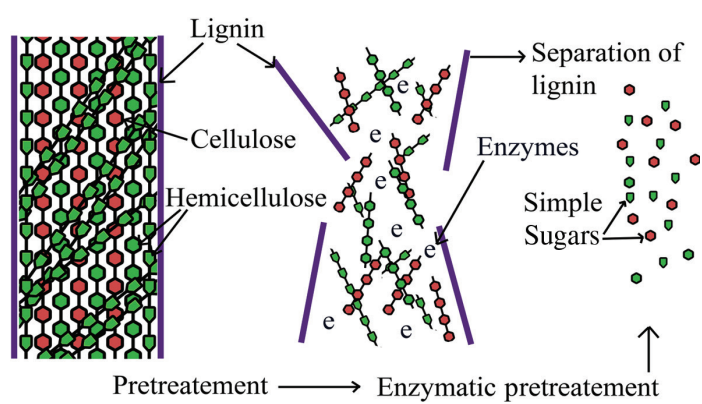

Figure 2: Pretreatment of lignocellulosic biomass to remove lignin and further enzymatic saccharification process to produce simple sugars. enzyme production (Cardona Alzate and Sánchez Toro 2006). In the last three decades, Trichoderma has been the most well-studied strains among various microorganisms for the production of cellulase and hemicellulase enzymes (Menon and Rao 2012). Although the enzymes produced by $T$. reesei are efficient, they suffer from low glucosidase activity and finally lead to incomplete hydrolysis of cellobiose in reaction (Menon and Rao 2012). Aspergillus is another well-known fungus for $\beta$-glucosidase production from complex lignocellulosic compounds (Taherzadeh and Karimi 2007). Sometimes, the enzyme mixture of both species plays the most efficient role in improved hydrolysis processes (Chen et al. 2008, Sateesh et al. 2012).

The most influencing process parameters such as temperature, $\mathrm{pH}$, mixing rates, substrate concentration, and cellulase enzyme loading determine simple sugar yields from enzymatic saccharification processes (Olsson and Hahn-Hägerdal 1996, Alkasrawi et al. 2003). In terms of substrate concentration, high solid loading [ $>15 \%(\mathrm{w} / \mathrm{v})]$ is effective to improve the process efficiency and economy (Zhang and Lynd 2010). Such environment-friendly high solid loading saccharification process comes up with lower capital investment costs due to the use of fewer reactors, less energy consumption during heating and cooling, and reduced disposal costs due to less usages of water (Zhang et al. 2013). However, the challenges associated with such high solid loading saccharification processes are increased viscosity due to difficulties in mixing, heat and mass transfer limitations, and inhibition of toxic components during fermentation (Alvira et al. 2013). Such drawback related to high solid loading could be dodged with the application of high enzyme dosages and novel process strategies. The fed-batch approach is considered as the more efficient process while dealing with high solid loading for various advantages (Hodge et al. 2009). Fedbatch feeding strategies provide sequential time-dependent addition of substrates to deal with the maximum concentration of substrate and to liquefy the substrate before next addition (Liu et al. 2017). The concept of fedbatch feeding strategies in high solid loading saccharification process is represented in Figure 3. Liu et al. (2015) applied fed-batch saccharification process with sugarcane bagasse with maximum $15 \%$ solid loading. In this study, viscosity-dependent sequential feeding was implemented with gradually less concentration $(8 \%, 7 \%$, and $6 \%$ ) of sugars. Maximum glucose concentration was achieved with $134.9 \mathrm{~g} / \mathrm{l}$ from total solid content of $36 \%$ and enzyme dosages of $8.5 \mathrm{FPU} / \mathrm{g}$. In a similar fed-batch saccharification process, time-dependent optimal solid loading of alkali-pretreated sugarcane bagasse was implemented by Gao et al. (2014) with enzyme loading of 10 FPU/g. Fresh 


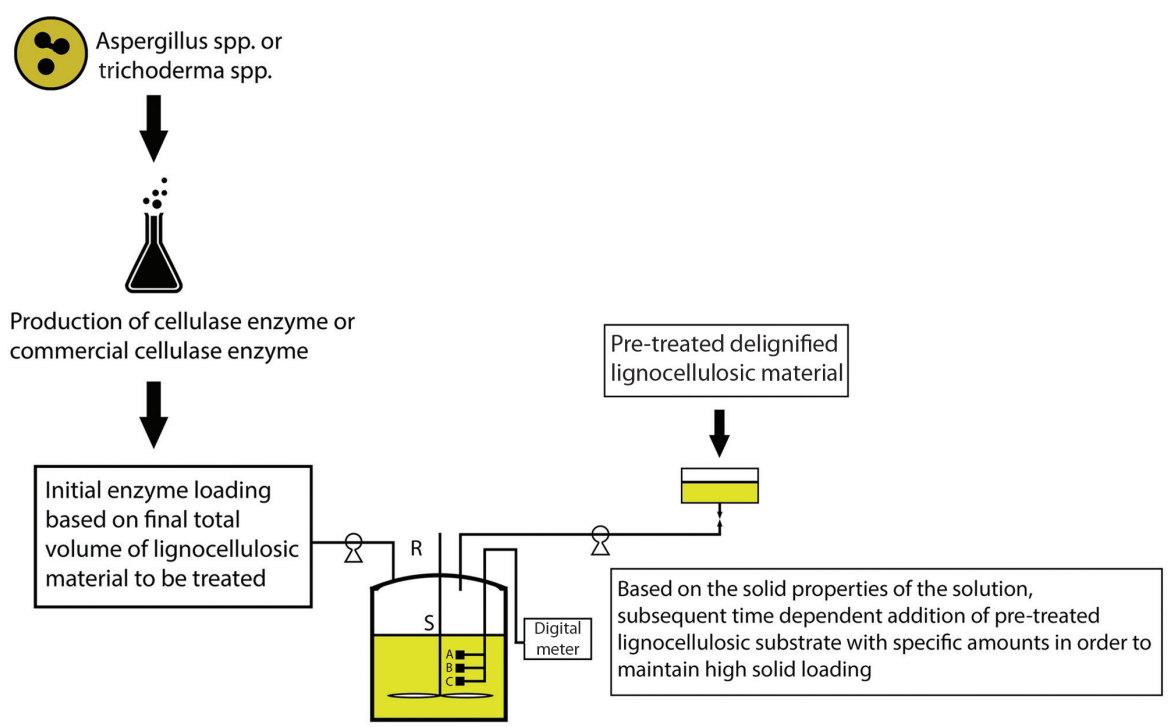

Figure 3: Concept of fed-batch feeding strategies in high solid loading saccharification process.

solids of $7 \%$ were consecutively added at the intervals of 6,12 , and $24 \mathrm{~h}$ to achieve maximum $33 \%$ solid loading, $129.50 \mathrm{~g} / \mathrm{l}$ glucose concentration, and $56.03 \mathrm{~g} / 1$ xylose concentration at the end of the process. Sugiharto et al. (2016) clearly highlighted that enzyme feeding strategies can play an important role in fed-batch enzymatic hydrolysis process. In this study, commercial Cellic CTec 2 enzyme with dosages of $185 \mathrm{FPU} / \mathrm{ml}$ from Novozymes was implemented on $25 \%$ solid loading for $40 \mathrm{~h}$ to increase the digestibility and produce glucose concentration up to $26 \%$ and $12 \%$. Liu et al. (2017) evaluated the effect of solvent water on high solid saccharification process and it was concluded that solvent such as oleyl alcohol instead of water as solvent was inhibitory for cellulose hydrolysis. Wang et al. (2017) implemented an applied electric field to improve the saccharification of lignocellulosic substrate. Conventionally, batch saccharification process is considered as time taking as common time duration is 3-7 days and high solid loading is required in that process to achieve acceptable conversions (Selig 2008). As an suitable alternative to batch saccharification, continuous countercurrent saccharification was proposed by Zentay et al. (2016) while working with commercial $\alpha$-cellulose. As the utilization of commercial enzyme in saccharification process is considered as expensive, production of enzymes from cheap substrate, immobilization of enzymes, and recycle and reuse of the enzymes are alternative solutions to make the enzymatic saccharification process commercially more viable. Aligned with the same concept of enzyme recycling, Pihlajaniemi et al. (2014) developed solid recycling process for improved enzymatic saccharification process. During saccharification process, cellulase enzyme can be present in soluble form and the maximum amount of insoluble cellulase enzyme can be adsorbed onto the solid substrate. The recycling of such enzyme adsorbed solid substrate after hydrolysis can be considered as an suitable approach for enzyme recovery and reuse (Pihlajaniemi et al. 2014). To improve the enzymatic hydrolysis process, Van Dyk and Pletschke (2012) emphasized that surfactants are normally used as common additives to prevent the nonproductive adsorption of enzymes on solid substrate.

Although acid hydrolysis occurs comparatively in a shorter duration of time, certain drawbacks make the process industrially unfit. For diluted acid hydrolysis process, the biggest limitation is how to increase the glucose yields to more than $70 \%$ while minimizing glucose decomposition and maintaining high cellulose hydrolysis rate. On the contrary, expensive concentrated acid hydrolysis process leads to environmental and corrosion problems. Alternatively, as enzymatic hydrolysis is carried out at mild environmental conditions with regard to $\mathrm{pH}$ and temperature and involves low energy requirement, the utility cost of the process is considered much lower than acid hydrolysis (Al-Zuhair et al. 2013). However, the obstacles that have been observed in enzymatic hydrolysis lack an ideal reactor system, slow reaction rate, ineffective use of cellulase, and enzyme inhibition by cellobiose and glucose (Noble et al. 1990). Even xylo-oligosaccharides such as xylose produced during hemicellulose hydrolysis create a higher level of cellulase enzyme inhibition than xylin (Qing et al. 2010). Still now, batch reactors are mostly used for industrial enzymatic process. The difficulties that have been encountered with batch reactors 
are batch-to-batch oscillations, high cost of labor, frequent startup and shutdown problems, and the need to recover enzyme or preparation of enzyme after each batch (Prazeres and Cabral 1994). Again, using the free form of enzyme in a continuous process is economically unfeasible as free enzymes leave from the outlet of the continuous process. MBR is considered as one of the relevant approaches to address all those issues involved in enzymatic saccharification process. It facilitates the reuse and recycle of expensive enzymes while avoiding product inhibition problem by instant permeation of reaction products such as cellobiose and glucose. In the last few decades, continuous MBR has been developed to improve enzymatic hydrolysis operations (Mameri et al. 2000). On the contrary, MBR also facilitates saccharification reaction in the form of enzyme immobilization where membrane can act as solid surface where the chemical and physical attachment of the enzyme and product removal can be done simultaneously.

\subsection{Conventional fermentation technology to produce bioethanol}

In this process, depending on the compositions of lignocellulosic hydrolyzate materials, the conversion of sugars to ethanol is normally performed through a biological pathway specifically by bacteria or yeast. Parameters such as process economics, kinetic properties of the microorganism, and types of lignocellulosic hydrolyzate help to determine the suitable mode of fermentation among batch, fed-batch, and continuous modes.

For a commercially vibrant bioethanol production process, an ideal microorganism plays most the vital role. It should have broad substrate conversion capacities and high ethanol yield productivity and it must have the ability to withstand high processing temperature and high concentration of ethanol. Mostly, Saccharomyces cerevisiae commonly known as industrial yeasts and Zymomonas mobilis have been used for bioethanol production in brewery and wine industries (Limayem and Ricke 2012). The main limitation of such organisms is that they are capable of fermenting hexose sugars such as glucose to ethanol but unable to ferment pentose sugars such as xylose. Pentose substrates such as xylose can be metabolized by Pichia stipitis, Candida shehatae, and Candida parapsilosis to produce bioethanol. Recently, recombinant $S$. cerevisiae carrying heterologous gene for $\mathrm{XR}$ and $\mathrm{XDH}$ from $P$. stipitis and xylulokinase (XK) have been developed to produce bioethanol from both hexose- and pentose-based substrates (Katahira et al. 2006). Compared to conventional yeasts, bacteria such as Z. mobilis, Escherichia coli, and Klebsiella oxytoca are well known for their rapid fermentation of simple sugars. Saez-Miranda et al. (2006) clearly demonstrated that, compared to traditional S. cerevisiae, Z. mobilis can achieve 5\% higher bioethanol yield and fivefold higher volumetric productivity of bioethanol from glucose-based solution. For the fermentation of pentose and hexose sugars from lignocellulosic hydrolyzate material, the utilization of mixed microbial population has been preferred more. Chandel et al. (2011) achieved a maximum $15 \pm 0.92 \mathrm{~g} / \mathrm{l}$ bioethanol production from Saccharum spontaneum implementing cocultures of $P$. stipitis and thermotolerant $S$. cerevisiae. In a similar experimental investigation with $S$. spontaneum, Singh et al. (2014) developed a sequential coculture system with $P$. stipitis and $Z$. mobilis for better utilization of total sugars. Through the successful applications of metabolic engineering, the $E$. coli strain was developed with the ability to ferment a wide variety of sugars with no additional requirements (Doelle et al. 1989). Thermophilic microorganisms such as Clostridium thermocellum, Thermoanaerobacterium saccharolyticum, Thermoanaerobacterium thermosulfurigenes, Thermoanaerobacterium ethanolicus, Thermoanaerobacterium pseudoethanolicus, Thermoanaerobacterium mathranii, Thermoanaerobacter pentosaceus, Thermoanaerobacter brockii, Caloramator viberbiensis, Caloramator fervidus, and Paenibacillus spp. have been extensively investigated for improved production of ethanol at high temperatures (Arora et al. 2015). Kluveromyces marxianus emerge as the most promising yeast, which can grow at higher temperature of $45^{\circ} \mathrm{C}-52^{\circ} \mathrm{C}$ and can effectively produce bioethanol along with enzymatic saccharification process. In an experimental SSF study with sugarcane bagasse, Lin et al. (2013) achieved ethanol concentration and theoretical yield up to $24.6 \mathrm{~g} / \mathrm{l}$ and $79 \%$, respectively, using $K$. marxianus at $42^{\circ} \mathrm{C}$ in a rotary drum reactor.

The fermentative conversion process of biomass to ethanol can be carried out with three different process configurations such as SHF, SSF, and consolidated bioprocessing (CBP) approach. SHF is basically a two-stage process. First, using suitable enzymes, cellulose and hemicellulose materials are hydrolyzed to reducing sugars. In the next stage, such reducing sugars are then converted into ethanol by fermentation process using suitable microorganism. Both processes (i.e. enzymatic hydrolysis and fermentation) can be performed under their optimal conditions (temperature, $\mathrm{pH}$, nutrient composition, and solid loading). It is considered as the main advantage of this configuration as the optimum operating conditions of both processes differ considerably. The 
optimum temperature for enzymatic hydrolysis is about $50^{\circ} \mathrm{C}$, which differs from fermentation temperature at $28^{\circ} \mathrm{C}-37^{\circ} \mathrm{C}$. Moreover, the overall performance of the process is not affected as two processes are conducted separately in different vessels and hence hydrolyzing enzymes are not influenced by the presence of ethanol. On the contrary, the biggest drawback of the process is the inhibition of enzyme activity by increasing concentrations of released simple sugars in the vessel. Such inhibition process slows down the rate of cellulose hydrolysis. There are many reports suggesting that the economic investment is normally increased for SHF due to the use of more than one vessel at different times. Another biggest drawback of SHF process is that, when it is performed under high solid loading condition, the activity of cellulolytic enzymes gets reduced due to inhibition problem. To improve the rate of cellulose hydrolysis, the utilization of various surfactants such as Tween, polyethylene glycol, or ionic liquids can play a vital role while reducing enzyme attachment to lignin (Eriksson et al. 2002). Dahnum et al. (2015) compared the performance of both SHF and SSF processes on empty fruit bunch and $4.74 \%$ ethanol was achieved at $72 \mathrm{~h}$ of SHF experiments, whereas $6.05 \%$ ethanol was obtained at $24 \mathrm{~h}$ of SSF process. In a similar comparative experimental observations, Kelbert et al. (2015) achieved 2.3-fold higher ethanol concentration from SHF process of non-nutrient-supplemented Eucalyptus globules and the result was comparatively unfavorable than the SSF process. In another comparative experimental study of SHF (Cotana et al. 2015) with the advanced SSSF process, the overall ethanol yield achieved was $13.17 \mathrm{~g}$ ethanol from 100 g Cynara cardunculus L., which was slightly lowered than the result (13.64 $\mathrm{g}$ from $100 \mathrm{~g}$ ) achieved from the SSSF process.

SSF is a single-stage process where enzymatic hydrolysis and fermentation for bioethanol production is carried out in a combined manner in a same vessel. SSF is a more promising and advantageous approach with respect to SHF because of low production cost, less processing time, less reactor volume, higher ethanol productivity, lower requirement of enzyme, ability to overcome enzymatic inhibition by simultaneous endproduct removal, and lower requirement for sterile conditions as bioethanol is produced immediately with glucose conversion (Jahnavi et al. 2017). The saccharification process involving enzymatic reaction is normally carried out around $50^{\circ} \mathrm{C}$, whereas the temperature normally maintained for ethanol fermentation is between $28^{\circ} \mathrm{C}$ and $37^{\circ} \mathrm{C}$ for most fermenting organisms. It is a difficult task to lower the optimum temperature of cellulases through protein engineering. Accordingly, high-temperature fermentation has been the major priority for the SSF process and thermotolerant yeast strains can play a major role in that process. In an experimental observation, Saini et al. (2015) showed that a thermotolerant yeast strain such as K. marxianus DBTIOC35 was effective to produce a maximum $29 \mathrm{~g} / \mathrm{l}$ bioethanol with $73 \%$ yield through SSF experiments carried out at $42^{\circ} \mathrm{C}-45^{\circ} \mathrm{C}$ using wheat straw as substrate. To deal with the difference between the optimal temperature of the enzyme action and microbial fermentation to produce bioethanol, different efficient and modified SSF strategies have been developed. The process configuration of SSF with short presaccharification or semisimultaneous saccharification (PSSF or SSSF) has been developed as a good alternative to enhance higher ethanol concentration, yield, and productivity (Gonçalves et al. 2014, Shahsavarani et al. 2013). Gonçalves et al. (2014) showed that a short presaccharification step at $50^{\circ} \mathrm{C}$ for $8 \mathrm{~h}$ in the SSSF process with three microorganisms (S. cerevisiae, P. stipitis, and $Z$. mobilis) had a positive effect to increase the overall yield of bioethanol from $79.27-84.64 \%$ to $85.04-89.15 \%$. In a similar study with coconut fiber, Gonçalves et al. (2016) showed the hydrothermal pretreatment catalyzed with $\mathrm{NaOH}$ (HPCSH) followed by SSF (SSSF) process using $S$. cerevisiae, $P$. stipitis, and $Z$. mobilis microbes was useful to achieve high yields of bioethanol of $91.17 \%$ and $91.03 \%$. Among the existing process of the modified SSF approach, simultaneous saccharification and cofermentation (SSCF) has been most feasible approach to convert both hexose and pentose sugars to increased concentration of lignocellulosic bioethanol. For the bioconversion of both types of pentose and hexose sugars in SSCF processes, ideal coculture fermentation with combinations of suitable microorganisms, which do not effect each other's metabolic activities, are mainly required (Chandel et al. 2011, Singh et al. 2014). Singh et al. (2014) performed sequential coculture fermentation system with $P$. stipitis and $Z$. mobilis in a 71 bioreactor and the average ethanol yield and productivity were $0.453 \mathrm{~g} / \mathrm{g}$ and $1.580 \mathrm{~g} / \mathrm{l} \mathrm{h}$ from kans grass-based substrate. Chandel et al. (2011) made efforts toward coculture fermentation system with $P$. stipitis and thermotolerent $S$. cerevisiae with an appropriate ratio. The achieved yield and concentration of ethanol were $0.49 \mathrm{~g} / \mathrm{g}$ and $15 \mathrm{~g} / \mathrm{l}$ from wild sugarcane materials and the results were comparatively better than the reports where the same microorganisms were used separately for the same purpose. There are some studies of novel SSCF processes (Olofsson et al. 2010, Zhang and Lynd 2010) where the combination of enzyme and xylose feeding strategies is implemented with recombinant xylose fermenting strain to achieve high ethanol titers. Among all existing process configurations of SSF, repeated-batch fermentation 
with immobilized microorganism and fed-batch SSSF approach are the other two promising and advanced approaches. SSF with repeated-batch fermentation with immobilized microorganism is comparatively disadvantageous as it is time consuming and, due to transport limitation, conversion efficiency will be comparatively less, whereas fed-batch SSSF scheme largely reduces time and costs associated with the process (Hasunuma et al. 2013). To produce concentrated bioethanol at the end of the process, high substrate concentration in terms of solid loading is useful and it will be instrumental to reduce the operational cost and energy consumption during the final purification stages. Again, microbial cell viability and solid loading are totally correlated with cellulase dosages (Tomás-Pejó et al. 2008). To deal with the proper enzymatic dosage and suitable solid loading, appropriate feeding strategy for enzymes in fed-batch SSF appears to be effective to achieve higher ethanol yield (Menon and Rao 2012). Lu et al. (2010) achieved ethanol concentration of $49.5 \mathrm{~g} / \mathrm{l}$ from $30 \%$ cumulative and time-dependent insoluble solid feeding in fed-batch enzymatic hydrolysis and fermentation approach. A similar experience of increasing ethanol yield was obtained by Hoyer et al. (2010) when pretreated spruce substrates as feed was added manually at different time intervals of fed-batch SSF process. High substrate concentration during fermentation became inhibitory for microbial growth and it leads to low ethanol yield. To deal with such problem, fed-batch SSSCF or PSSCF could be the best possible solution for ideal substrate conversion. Lu et al. (2013) clearly showed how substrate feeding strategies in different time intervals of enzymatic prehydrolysis periods in fed-batch SSSF process were helpful to achieve ethanol concentration of $39.4 \mathrm{~g} / \mathrm{l}$. Fed-batch SSSF process is efficient in achieving high ethanol concentration, but the effectiveness can be further strengthened through integrating cofermentation strategies into it. The concept of such advantageous fed-batch SSSCF approach is represented in Figure 4. Considering all existing process configurations of SSF approaches for lignocellulosic bioethanol production, the fed-batch SSSCF approach with proper enzymatic dosage and suitable solid loading is the most advanced biorefinery approach, which has not been reported so far.

To improve microbial performance for efficient cellulose hydrolysis and increasing energy efficiency during fermentation process, enzyme production, saccharification, and fermentation can be further consolidated into a single process. Such single-stage CBP has been increasingly recognized as the most potential and promising strategy to reduce costs and environmental impacts of the bioethanol production process (Tomás-Pejó et al. 2008,

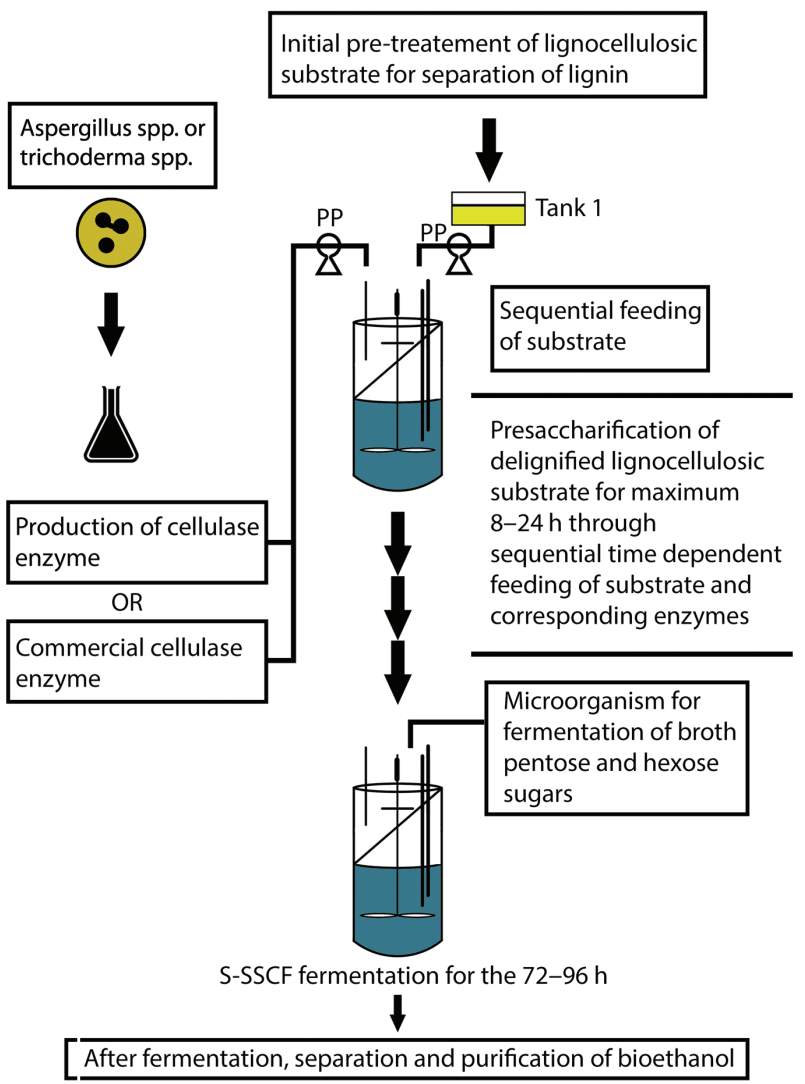

Figure 4: Concept of advantageous fed-batch SSSCF approach for lignocellulosic bioethanol production.

Hasunuma et al. 2013). The biological conversion of pretreated lignocellulosic substrate by one or more efficient organisms into bioethanol while hydrolyzing biomass with enzymes, produced on its own and fermenting those material, could offer a large number of advantages while promoting lignocellulosic bioethanol closer to market (Olson et al. 2012). The major advantages of CBP process include the reduction of capital investment, elimination of requirements associated with enzyme production, simplification of total reactions, improving hydrolysis efficiency, and reduction of contamination risk (Hasunuma and Kondo 2012, Hasunuma et al. 2013). The factors that make CBP technology more attractive are (1) suitability of high levels of enzyme production and enzymatic hydrolysis rate, (2) production of minimum level of toxic components inhibitory for CBP microorganisms, (3) cofermentation of hexose and pentose sugars while minimal degradation of carbohydrate fractions, and (4) tolerating high levels of endproduct (Parisutham et al. 2014, Den Haan et al. 2015). The major challenging feature of CBP is saccharification and fermentation usually carried out at common higher temperature and such drawback could be dodged using thermophilic CBP microbes. The capabilities 
of various fungi, such as Aspergillus, Fusarium, Monilia, Rhizopus, Neurospora, Trichoderma, Phlebia, and Mucor spp. as ideal CBP microorganisms have been reported for the improved conversion efficiency of cellulose to ethanol (Anasontzis et al. 2011, Hasunuma et al. 2013). More specifically, among thermophilic CBP microbes, $K$. marxianus appear to be the most promising microorganisms, which can grow well at higher temperature $\left(45-52^{\circ} \mathrm{C}\right)$ and can efficiently produce ethanol with higher titer (Hasunuma and Kondo 2012). Hong et al. (2007) identified K. marxianus as a high-efficiency recombinant strain that can directly produce $43.4 \mathrm{~g} / \mathrm{l}$ ethanol from $100 \mathrm{~g} / \mathrm{l}$ cellobiose at high temperature $\left(45-50^{\circ} \mathrm{C}\right) \mathrm{CBP}$ process.

Although engineering yeast, filamentous fungi, and bacteria have been used significantly as CBP microbes, process-ready improved microorganisms for the production of higher level of bioethanol is still under development. Among common category $1 \mathrm{CBP}$ microorganisms, $C$. thermocellum (Lynd et al. 2005), T. mathranii (Taylor et al. 2009), and cellulolytic fungi such as T. reesei (Huang et al. 2014) are already recognized, but to achieve high yield and concentration of bioethanol, still intensive research is required in this field. Xu et al. (2009) acknowledged that T. reesei as an efficient producer of cellulase can be used for bioethanol production through CBP approach with low ethanol yield. For improving performance of overall CBP process with both cellulose and hemicellulose degradation and conversion in to bioethanol, Fusarium oxysporum is considered as the best filamentous organism for CBP process. Paschos et al. (2015) showed the efficiency of $F$. oxysporum in improved ethanol production process with final ethanol concentration of $58 \mathrm{~g} / \mathrm{l}$. In a case study, Mattila et al. (2017) reported the direct bioconversion of lignocellulosic waste materials by phlebioid fungal species without involving any pretreatment of substrate, whereas achieved bioethanol yield (10.4\%) and concentration $(5.9 \mathrm{~g} / \mathrm{l})$ were comparatively low. In another CBPbased experimental observation with Phlebia sp, Kamei et al. (2012) obtained a similar low ethanol concentration of $8.4 \mathrm{~g} / \mathrm{l}$ from $20 \mathrm{~g} / \mathrm{l}$ unbleached hardwood kraft pulp. To make CBP-based bioethanol production industrially acceptable, there must be a demand to improve the performance of CBP process with suitable process configuration involving ideal microorganism. Among advanced CBP processes, cell recycling batch fermentation (CRBF) as proposed by Matano et al. (2013) was instrumental to achieve enhanced bioethanol concentration with reduce time and costs. The concept of advanced CRBF under CBP is represented in Figure 5.

The fermentative biochemical route for production of biofuel is considered advantageous, as it has a greater

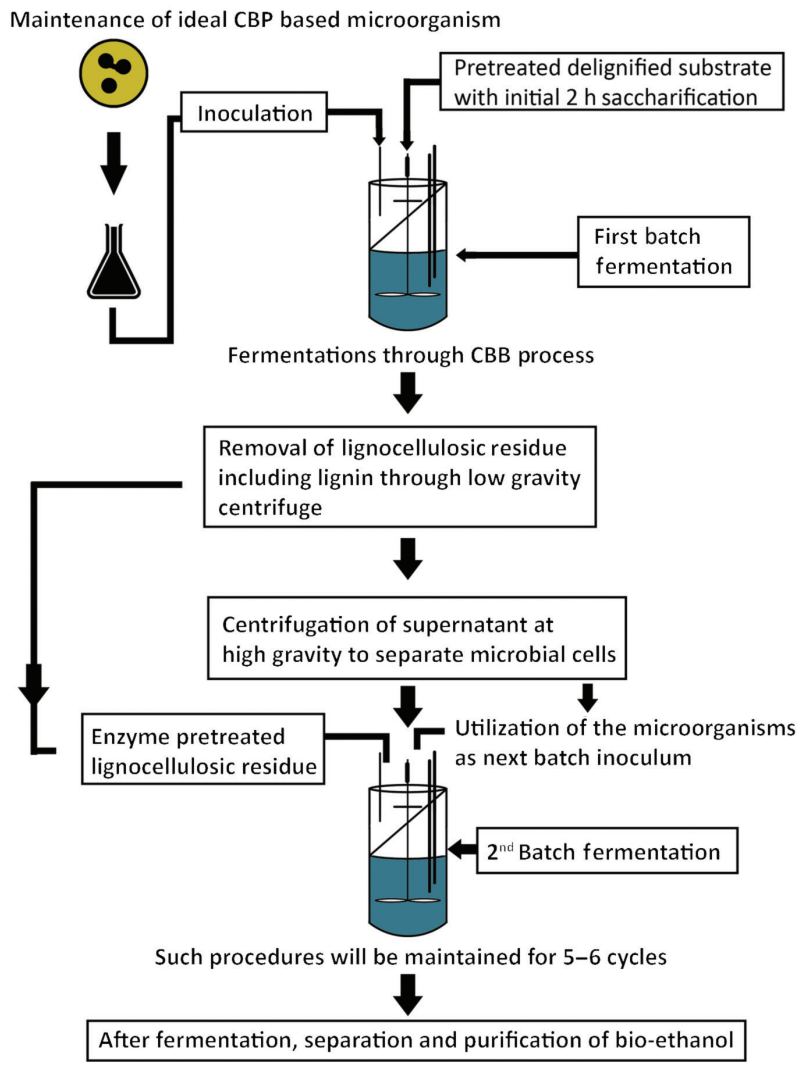

Figure 5: Concept of advanced CRBF strategy under CBP for lignocellulosic bioethanol production.

probability of cost reduction compared to thermochemical route. Chemicals such as phosphorous and nitrogen generated during thermochemical route are normally released to the atmosphere, which leads to additional eutrophication and acidification (Limayem and Ricke 2012). On the contrary, the biochemical route exhibited the requirement of higher quantity of water than the thermochemical route. In the near future, water availability could become a major concern if sustainable water utilization practices are not carried out in agricultural field. Even the utilization of higher water content causes lower concentration of fermentable sugars in prehydrolyzates, which finally leads to low concentration of ethanol after fermentation. Most of the conventional methods cannot concentrate sugar solution while separating inhibitors. Cell recycle MBR system can overcome this problem and enable high cell densities inside the reactor. High cell density fermentation system allows significantly faster fermentations than lower cell concentration system. Hence, higher production goals can be achieved in a comparatively smaller reactor and in shorter time duration (Westman and Franzén 2015). At the same time, such bioreactor allows easier separation of endproducts, inhibitors that can strongly inhibit the 
fermentation system. The implementation of such kind of process design will definitely be helpful to decrease the production cost of ethanol.

\subsection{Conventional separation process}

Distillation is the conventional separation and purification process of bioethanol from aqueous fermentation broth. Based on the different volatilities, ethanol is being separated from aqueous mixture by fractional distillation. Based on the boiling point of ethanol $\left(78.3^{\circ} \mathrm{C}\right)$, which is lower than the boiling point of water $\left(100^{\circ} \mathrm{C}\right)$, ethanol will be converted to steam before water during boiling and can be separated by condensation. Continuous distillation column system with multiple effects is normally used in biorefineries and in large-scale industries (Kent et al. 1994). Most volatile components from the liquid mixture are separated from the top of the column during distillation. The main limitation of the distillation process is to separate the components with the same boiling point from liquid mixture. Industrially applicable anhydrous ethanol, which contains $99.5 \%$ ethanol by volume and water content not more than $0.5 \%$, can be produced through some advanced distillation processes such as adsorption distillation, azeotropic distillation, diffusion distillation, extractive distillation, membrane distillation, and vacuum distillation (Kumar et al. 2010).

\section{Specific limitations of conven- tional processes}

Pretreatment is considered as one of the most important stages in lignocellulosic bioethanol production. Inefficient pretreatment processes can lead to the production of toxic substances, which finally inhibit microbial metabolism (Kodali and Ravindra 2006). At the same time, pretreatment processes are also considered as one of the most expensive processing steps in overall conversion processes of biomass to fermentable sugars and finally ethanol (Zheng et al. 2009). Some specific limitations and disadvantages are involved with every individual pretreatment process and it is important to overcome those limitations with extensive research approaches. Mechanical pretreatment is considered as high energy-consuming procedure and hence not economically feasible (Taherzadeh and Karimi 2008). Under chemical pretreatment categories, alkali treatment is considered as a long residence timedependent process, whereas mineral acids are considered somewhat hazardous, toxic, and corrosive (Menon and Rao 2012). Although steam explosion under physicochemical pretreatment is recognized as most effective and demonstrated on a commercial scale at Masonite plants, it leads to incomplete disruption of the lignin-carbohydrate matrix. Ozonolysis and organoslv are basically regarded as expensive physicochemical pretreatment methods, as organosolv suffers from increase energy consumption and high efficiency cooling systems are required for exothermic ozonolysis process (Mesa et al. 2016, Travaini et al. 2016). Existing biological pretreatment processes require modification to deal with its nature of slow rate of hydrolysis. In comparison to diluted acid hydrolysis, concentrated acid (30-70\%) hydrolysis is processed at comparatively low temperature (e.g. $40^{\circ} \mathrm{C}$ ) and higher sugar yield can be obtained. However, the biggest drawback of acid hydrolysis is that it makes the equipment corrosive and partially degrades the inherent sugars (Jahnavi et al. 2017). Compared to acid hydrolysis, enzymatic hydrolysis is more specific in saccharification process and normally carried out in mild conditions at $40^{\circ} \mathrm{C}-50^{\circ} \mathrm{C}$, but sometimes it suffers from product and substrate inhibition problems. Among various fermentation strategies, SHF suffers from endproduct inhibition problem and finally resulting in lower ethanol yield (Balat and Balat 2008). Although SSF is considered for higher ethanol yield, adjusting the difference between optimum temperature conditions for both fermentation and hydrolysis becomes difficult (Bjerre et al. 2000). Similarly, CBP suffers from the availability of suitable thermophilic microbes (Hasunuma and Kondo 2012). Conventional distillation for the separation and purification of bioethanol is considered as energy consuming, and sometimes, components from mixtures cannot be separated in the normal way and hence require a more advanced approach. More specific limitations of conventional operating systems are mentioned in Table 1. Research efforts have been made toward improving various stages of bioethanol production, but still there is a much need to improve overall process efficiencies and economics while adopting advanced and intensified process strategies.

\section{Emerging membrane processes for lignocellulosic bioethanol production}

Feasibilities to separate extracts or products of natural essence from a heterogeneous mixture at ambient condition promote membrane technology to become the most preferable technology in numerous industrial applications. Already, membrane filtrations were extensively 
Table 1: Specific limitations of different stages of lignocellulosic bioethanol production process.

\begin{tabular}{|c|c|c|}
\hline Processes & Limitations and disadvantages & Reference \\
\hline \multicolumn{3}{|c|}{ Pretreatment processes } \\
\hline Mechanical & Higher power consumption than inherent biomass energy & (Menon and Rao 2012) \\
\hline \multirow[t]{3}{*}{ Chemical } & Formation of irrecoverable salts and interfering during pretreatment & (Hendriks and Zeeman 2009) \\
\hline & Ionic liquids are expensive; recycling decreases the efficiency of process & (Singh and Simmons 2013) \\
\hline & $\begin{array}{l}\text { Ozonolysis is highly flammable and corrosive and requires a high } \\
\text { amount of ozone }\end{array}$ & (Travaini et al. 2016) \\
\hline \multirow[t]{3}{*}{ Physicochemical } & $\begin{array}{l}\text { Steam explosion needs high equipment cost and partial hemicellulose } \\
\text { destruction }\end{array}$ & (Brodeur et al. 2011) \\
\hline & LHW is for specific lignocellulosic biomass and high water consumption & (Zhuang et al. 2016) \\
\hline & AFEX is less effective for higher lignin content material & (Sarkar et al. 2012) \\
\hline Biological & Longer duration time & (Moreno et al. 2015) \\
\hline \multicolumn{3}{|l|}{ Hydrolysis process } \\
\hline Acid hydrolysis & Non-environment-friendly process & (Sun and Cheng 2002) \\
\hline Enzymatic & Considered expensive and takes longer duration & (Jahnavi et al. 2017) \\
\hline \multicolumn{3}{|c|}{ Fermentation processes } \\
\hline SSF & Difference in optimum conditions in enzymatic action and fermentation & (Balat and Balat 2008) \\
\hline SHF & Chances of contamination in long period process & (Das Neves et al. 2007) \\
\hline CBP & Development of highly efficient recombinant microorganism & (Menon and Rao 2012) \\
\hline \multicolumn{3}{|l|}{ Separation process } \\
\hline Distillation & Process is temperature sensitive & (Limayem and Ricke 2012) \\
\hline
\end{tabular}

implemented in a large number of industrial applications including seawater desalination, petroleum refining, paint and solvent recovery in chemical industry, clarification of corn syrups such as dextrose and fructose in starch and sweetener industry, concentrating various sugar solutions in sugar industry, high-purity applications in power industry, and manufacturing high-value products such as antibiotics in pharmaceutical industry and in different processes in food and beverage industry (Envitech 2013, AMTA 2014). Membrane technology has been considered as the most selective and energy-saving unit operation in many industrial processes and also considered to have potential applications in bioethanol industry (Lipnizki 2010). Membrane-based processes were already proposed for the enhanced recovery of conventional grain (starch)-derived first-generation biofuel in the US (Water World 2010). Such environment-friendly clean process can be easily coupled with different operations and can produce high-quality products with variable operating conditions. Involvement of low labor and maintenance cost due to minimal maintenance requirement and for intensified space requirement makes the membrane technology more attractive for different industrial applications. In particular, high-efficiency (membrane area per reactor volume) simpler modular operations and flexibilities in designing systems with easy scale-up make membrane technology perfectly suitable for "second-generation" biofuel production, specifically at the industrial scale. Membrane separation technologies can play the most useful role toward the improvements of individual stages involved in lignocellulosic bioethanol production process (Chapman et al. 2008).

MBR plays the most important role in filtration, product recovery, and cell separation or retention while facilitating the integration of membrane module with the bioreactor. MBR configuration includes reservoirs for the feed and permeates, high-pressure pump, and high pressure regulators or gauges. Different membrane modules such as flat sheet module, spiral-wound module, tubular membrane module, and hollow-fiber membrane modules were designed based on high membrane surface-to-volume ratio to facilitate adequate structural support to a thin membrane to withstand operating pressure, to maintain low pressure drop on concentrate side, and to provide provision for back flushing. Immersed or submerged MBR (iMBR) and side-stream external loop MBR (sMBR) are two specific pressure-driven MBR categories, generally used for a wide range of applications from wastewater treatment processes to bioethanol production in batch, fed-batch, and continuous fermentation mode (Judd and Judd 2011, Carstensen et al. 2012). For iMBR, submerged membrane module can be present in immersed condition inside the bioreactor, whereas, for sMBR, membrane module is normally attached as a separate compartment assembled with the main bioreactor (Mahboubi et al. 2016). The sMBR setup is considered comparatively more energy consuming as it requires pumping of large-medium volume through external loop to cross-flow modular setup (Hai et al. 2013, Mahboubi et al. 2016). There are some 
conventional membrane separation processes such as MF, UF, NF, and pervaporation that have been successfully implemented in different stages of bioethanol production process. Mass transport of the cells, colloidal matters, substrate, and product through the MF mechanism is based on the size-exclusion mechanism and dependent on specific membrane and cake resistances (Dey and $\mathrm{Pal}$ 2013). UF mechanism is specifically useful for the separation of high molecular weight products such as polymers, proteins, and colloidal materials. The transport mechanism of such pressure-driven membrane process is also affected due to concentration polarization or the formation of incompressible gel layer. The transport mechanism of uncharged solutes through NF membrane occurs through diffusion and convection mechanism, whereas the transport of charged solute is mainly managed by the Donnan exclusion principle (Dey et al. 2012). Pervaporation is a vacuum-driven membrane separation technique that facilitates the separation of liquid components from an azeotropic mixture by phase change. The pervaporation process is effective enough to achieve pure ethanol while separating water from the ethanol-water mixture.

\subsection{Lignocellulosic substrates for membrane technology-based bioethanol production}

The most commonly used lignocellulosic carbon sources for bioethanol production process are rice straw, wheat straw, wheat bran, rice husk, banana waste, newspaper, sugarcane bagasse, and grasses. The compositions in terms of cellulose, hemicellulose, and lignin in those lignocellulosic feedstock were represented by Menon and Rao (2012) and Van Dyk and Pletschke (2012). The substrates that are mainly used for membrane technology-based bioethanol production are mainly pure and expensive carbohydrate sources such as glucose, fructose, sucrose, and lactose (Cheryan and Mehaia 1983, Hoffmann et al. 1985, Melzoch et al. 1991, Ding et al. 2012), industrial waste (whey and molasses), and sludge-based materials (Mehaia and Cheryan 1990, Tin and Mawson 1993, Kaseno and Kokugan 1997, Lee and Yeom 2007). Time-consuming and expensive pretreatment processes are the main prerequisites to avoid membrane fouling while working with waste materials. Specific agricultural lignocellulosic waste substances such as rice straw and wheat straw (Ishola et al. 2013, 2015a,b, Ylitervo et al. 2014, Zahed et al. 2016) have been mainly exploited in experimental studies of membrane reactor facilitated lignocellulosic bioethanol production process. In some experimental studies (Lee et al. 2000, Ylitervo et al. 2014), general lignocellulosic hydrolyzate materials were investigated in MBR-based bioethanol production process. Information related to specific lignocellulosic substrates used until now for MBR facilitated bioethanol production, maximum product concentration or productivity achieved, and membrane materials or modules used in those studies are represented in Table 2. Among the diverse lignocellulosic biomaterials, so many biomaterials such as perennial grass (e.g. kans grass and S. spontaneum) and coconut mesocarp, which are believed to be novel and potential nonfood lignocellulosic feedstock with great prospective for bioethanol production, have not been implemented until now for MBR-based bioethanol production process.

\subsection{Membrane-based advanced enzymatic saccharification}

Cellulases, which are considered as the most important and key enzymes for saccharification processes, are normally inhibited by the products of the enzyme substrate

Table 2: Lignocellulosic substrates used for membrane-based bioethanol production.

\begin{tabular}{llll}
\hline Medium (g/l) & $\begin{array}{l}\text { Maximum productivity/ } \\
\text { product concentration }\end{array}$ & $\begin{array}{l}\text { Membrane material/module/ } \\
\text { system }\end{array}$ & Reference \\
\hline Lignocellulosic hydrolyzate & $16.9 \mathrm{~g} / \mathrm{l} \cdot \mathrm{h}$ & Cylindrical ceramic tubes & (Lee et al. 2000) \\
Spruce sawdust & $7.94 \mathrm{~g} / \mathrm{l} \cdot \mathrm{h}$ & Flat sheet membrane/sMBR & (Ylitervo et al. 2014) \\
Spruce chips & $31.1 \mathrm{~g} / \mathrm{l}$ & Polyethylene/cross-flow & (Ishola et al. 2013) \\
Rice straw hydrolyzate & $55 \mathrm{~g} / \mathrm{l}$ & Cross-flow MF & (Ishola et al. 2015a,b) \\
Wheat straw & $35 \mathrm{~g} / \mathrm{l}$ & Polyethylene/cross-flow & (Brandberg et al. 2008) \\
Hydrolysis of spruce chips & $32 \mathrm{mmol} / \mathrm{g} \mathrm{h}$ & Cross-flow filter unit & (Saha et al. 2017a) \\
Sugarcane bagasse & $43.2 \mathrm{~g} / \mathrm{l}$ & Cross-flow MF/NF module & (Gaykawad et al. 2013) \\
Barley straw (acidic) & $31.1 \mathrm{~g} / \mathrm{l}$ & Commercial PDMS/pervaporation & (Gaykawad et al. 2013) \\
Barley straw (alkaline) & $18.5 \mathrm{~g} / \mathrm{l}$ & Commercial PDMS/pervaporation & (Gaykawad et al. 2013) \\
Willow wood chips & $11.5 \mathrm{~g} / \mathrm{l}$ & Commercial PDMS/pervaporation & (0’Brien et al. 2004) \\
Corn fiber hydrolyzate & $29-44 \mathrm{~g} / \mathrm{l}$ & PDMS/pervaporation module &
\end{tabular}


reactions. Utilization of the enzymes during saccharification process in the free form is not suitable due to its expensive nature. The alternative solution of such problem will be to recycle and reuse the enzymes. The retention of enzymes in free form rather than immobilized form is implemented more (Ishola et al. 2013, 2015a), as the immobilized form restricts its ability to penetrate the solid substrate; hence, expected conversion efficiency will be comparatively less (Al-Zuhair et al. 2013). Similarly, batch mode of enzymatic hydrolysis process for cellulose conversion is often restricted by product inhibition problem caused by newly generated hexose and pentose sugars (Andrić et al. 2010). To overcome such problems, research efforts have been directed toward the instant removal of simple sugars after the enzymatic saccharification process to maintain and even increase the conversion rate (Abels et al. 2013). To reuse and recycle the soluble enzyme solutions without using any expensive protein separation unit, MBR, specifically UF-based MBR system, can be successfully used to separate and reutilize the enzymes. Such design facilitates in the minimization of substrate utilization, instant separation of excess enzymes, and reutilization of such enzymes after enzyme substrate reactions. The basic configuration of such MBR system for enzymatic saccharification is represented in Figure 6. Such UF membrane-integrated continuous stirred tank bioreactor system was studied by Henley et al. (1980) for enzymatic saccharification. The investigations were carried out with four different lignocellulosic substrates and cellulase enzymes from Trichoderma spp. at a temperature of $50^{\circ} \mathrm{C}$ in an acetate buffer solution of $\mathrm{pH} 4.8$. Maximum conversion efficiency was achieved as $70 \%$ with powdered cellulose, which was used as one of the substrates among those four substrates. Comparatively less conversion efficiency of 53\% was achieved by Bélafi-Bakó et al. (2006) while working with tubular MBR system. Commercial enzyme solution from $T$. reesei was used in this study at $50^{\circ} \mathrm{C}$ and at $\mathrm{pH} 4.8$ in sodium acetate buffer solution. A similar type of UF-based MBR system was studied by Kinoshita et al. (1986) with cellulase enzymes obtained from Sporotrichum cellulophilum. Experimental investigations were carried out with increasing permeate flow rates and maximum glucose recovery was achieved at permeate flow rate of $15 \mathrm{ml} / \mathrm{h}$ up to $40 \mathrm{~h}$ of operation. Productivity was decreased after $40 \mathrm{~h}$ of operation due to the presence of proteases with crude enzymes, which finally leads to the deactivation of the enzymes. Similar correlation between glucose removal with increasing permeate flux was established by Alfani et al. (1982). Maximum conversion rate was increased from $2 \%$ to $5 \%$ at $25 \mathrm{~h}$ of operation interval with increasing permeate flux. Increasing permeate flux always leads to quick depletion of reaction volume inside of the reactor system and limited recovery of simple sugars. Such drawback could be dodged with an instant supply of fresh substrates and enzymes in fed-batch or continuous mode. Andrić et al. (2010) clearly explained that enzymatic conversation rate can be increased up to a certain extent with the addition of feed in increasing dilution rate. In the same direction, Kinoshita et al. (1986) observed that enzymatic conversion rate did not improve above feed flow rate of $15 \mathrm{ml} / \mathrm{h}$ when experiments were conducted with increasing feed flow rate of 3-30 ml/h. A slight contradictory result was obtained by Yang et al. (2006) when increased hydrolysis rate and increased glucose concentration were observed between low dilution rates of $0.057-0.075 / \mathrm{h}$, whereas comparatively lower

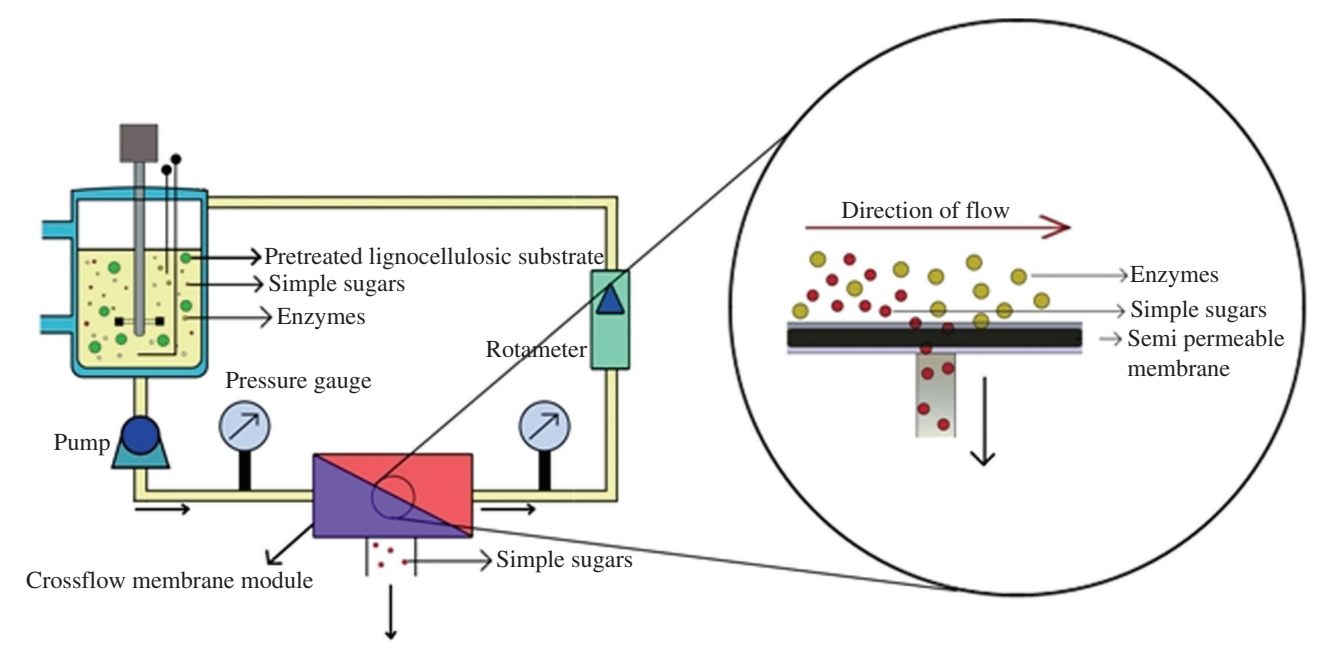

Figure 6: Basic configuration of MBR system for the enzymatic saccharification of lignocellulosic substrate. 
glucose concentration was achieved at higher dilution rates of $0.075-0.25 / \mathrm{h}$. Such experimental observations clearly suggest that increasing dilution rates beyond a certain limit can influence adversely in conversion rates and in achieving maximum glucose concentration.

It appears that enzymatic conversion rates are always positively influenced with feeding strategies of cellulosic substrates in fed-batch fermentation processes with suitable dilution rates (Andrić et al. 2010). Semicontinuous feeding strategies of substrates with initial enzyme loading and intermittent product removal have been normally adopted in advanced fed-batch enzymatic saccharification processes. Authors such as Kuhad et al. (2010), Soares et al. (2017), and Sugiharto et al. (2016) adopted different feeding strategies of lignocellulosic substrates in normal bioreactor facilitated fed-batch saccharification processes. To enhance the saccharification efficiency, increasing solid loading approach [from 12\% (w/v) to 33\% $(\mathrm{w} / \mathrm{v})]$ were adopted in high solid loading fed-batch saccharification processes (Gao et al. 2014). The best result was optimized when saccharification process was initiated with $12 \%(\mathrm{w} / \mathrm{v})$ solid loading and $7 \%$ fresh solids were gradually introduced at 6,12 , and $24 \mathrm{~h}$ to achieve final solid loading of 33\%. However, among the existing studies in the same research field, only few researchers highlighted the advantages of membrane-based fed-batch saccharification strategies in their observations. Ohlson et al. (1984) achieved improved initial hydrolysis rate and improved degree of enzymatic conversion from $40 \%$ in batch mode to $95 \%$ in semicontinuous fed-batch hydrolysis mode in an UF MBR system. Kinoshita et al. (1986) observed the lowering actual glucose concentration during fed-batch operations and it was termed as negative "dilution effect". MBR-based continuous hydrolysis process with continuous product removal is another advantageous strategy for improving saccharification efficiency. Advantages of such MBR-based continuous operations in lignocellulosic saccharification processes were already highlighted by Ghose (1969) 49 years ago. Ghose and Kostick (1970) explained in their report that, due to the rapid transport properties of reaction products, high conversion efficiency of $77 \%$ was achieved in continuous MBR system. With emerging features and advances in membrane materials, such MBRs can be scaled up from $300 \mathrm{ml}$ to $10 \mathrm{l}$ to facilitate saccharification processes, but still such kind of large-scale membrane processes deserves vigorous technoeconomic evaluation before implementation. UF membrane-integrated bioreactor system with working volume capacity of 2.51 was investigated by Gan et al. (2002) for the enzymatic degradation of $\alpha$-cellulose. Selection of suitable membranes with appropriate molecular weight cutoff facilitates the permeation of simple sugars such as glucose (molecular weight of $180 \mathrm{~g} / \mathrm{mol}$ ) and separation of fungal cellulase enzymes ranges from 35,000 to $65,000 \mathrm{~g} / \mathrm{mol}$ (Andrić et al. 2010). Normally, UF membranes with MWCO of $10 \mathrm{kDa}$ are more useful in the separation of glucose during hydrolysis and in achieving high conversion rate (Ohlson et al. 1984, Gan et al. 2002). Ohlson et al. (1984) pointed out that such MBR system is also successful for the enzymatic hydrolysis of lignocellulosic substrate without subsequent washing. Membrane cleaning and back-washing of membrane to remove deposited organic or inorganic material from its surface is one of the most important criteria to maintain the permeability of the membrane and it also determines the lifetime of a membrane. Membrane cleaning should be periodically done when permeate flow drops nearly about $10 \%$ and normalized pressure drop increases about $10 \%-15 \%$.

\subsection{MBRs for fermentative production of lignocellulosic bioethanol}

The most effective strategy for high titer bioethanol production is membrane-based cell recycle fermentation system. Such cell recycle MBR system plays the most important role in fermentative production of lignocellulosic bioethanol through an ecofriendly and sustainable route (Saha et al. 2017b). Cell recycle system not only reduces the time and costs associated with inoculum preparation but at the same time also ensures high biomass density fermentation system (Matano et al. 2013). In certain cases, highdensity fermentation system leads to the formation of high product concentration while fermenting inhibitory hydrolyzate. Another advantage of such membrane cell recycle fermentation system (MBR) is that the dilution rate is not dependent on the growth rate of the microorganism (Ylitervo et al. 2013). High dilution rates lead to maximum bioethanol productivity and yields (Ylitervo et al. 2014). Low dilution rates are the only possible operating conditions in which traditional continuous cultivation systems without cell recycle are successful (Brandberg et al. 2008). Taherzadeh et al. (2001) observed that, at low dilution rate of $0.1 / \mathrm{h}$, continuous fermentation of diluted acid hydrolyzate was successfully carried out by yeast strains, whereas at comparatively higher dilution rate of $0.2 / \mathrm{h}$ fermentation fails. During lignocellulosic fermentations, separation of microbial cells by conventional cell collection procedures from unutilized lignocellulosic residue is a difficult task. Considering this difficulty, Matano et al. (2013) developed two-phase separation of lignocellulosic residues from yeast cells in high solid loading lignocellulosic bioethanol 
A

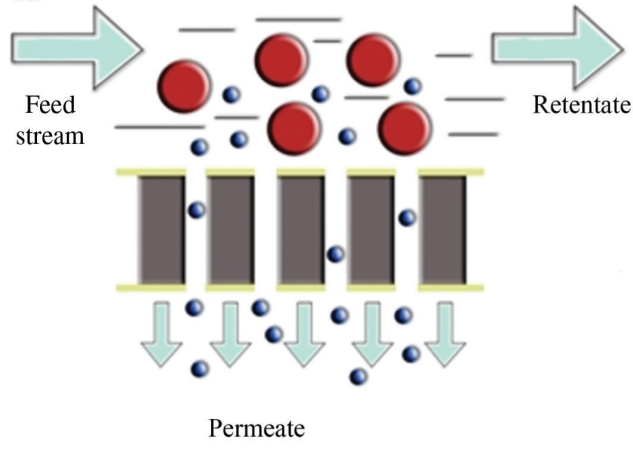

B

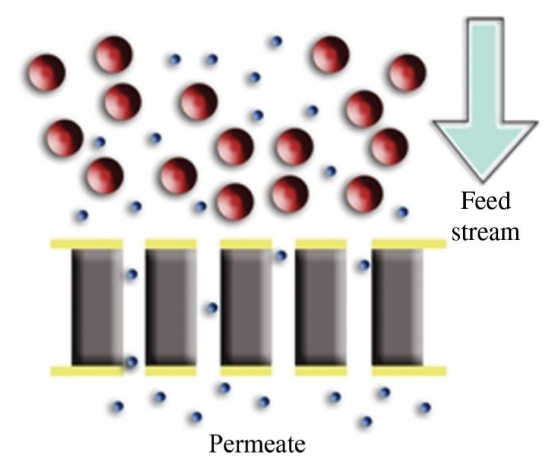

Figure 7: Mechanism of membrane filtration operations: (A) cross-flow mode and (B) dead-end mode.

production process. High solid loading with high cell density microbial culture system in MBR can lead to membrane fouling, which finally declines the flux during long operational time and hence restricts its credibility in largescale commercial applications. Soluble microbial products produced during fermentation normally get adsorbed and deposited on the membrane surface to form a biofilm layer. Several strategies are present to restrict membrane fouling problem, and among them, the selection of proper membrane material and proper operational conditions based on the application helps to mitigate the problem up to large extent. Operational conditions including low transmembrane pressure, low shear rate, and high cross-flow sweeping action in cross-flow operations rather than dead-end operations help to control membrane fouling (Wei et al. 2014). Basic membrane operations in cross-flow and deadend modes are represented in Figure 7. In dead-end mode, feed flows directly perpendicular to the filter medium and resistances of the liquid flow increase with rapid cake formation. In cross-flow mode, feed flow is tangential to the filter medium. To avoid membrane fouling, Ishola et al. (2015a) implemented a novel concept of forward flow operation for every $4 \mathrm{~min}$ followed by the reverse flow of $1 \mathrm{~min}$ in 2.51 Minifors, Switzerland MBR. Stepwise addition of the substrate was maintained in such advanced membrane-based SSFF strategies where both glucose and xylose were converted to bioethanol. Similar cofermentation strategy was also adapted by Mahboubi et al. (2016) in integrated permeate channel (IPC) MBR system. Such continuous membrane-based fermentation system comes up with total consumption of glucose, $83 \%$ consumption of xylose, and $83 \%$ theoretical bioethanol yield. While producing $99.28 \pm 0.68 \mathrm{~g} / \mathrm{l}$ of bioethanol from sweet sorghum stem juice, Thani et al. (2017) clearly indicated that such kind of membrane-based continuous operations plays the most instrumental role in high titer production. While operating with lignocellulosic substrate such as sugarcane bagasse in similar membrane-integrated continuous fermentation system, comparatively remarkable bioethanol concentration $(43.2 \mathrm{~g} / \mathrm{l})$ was achieved by Saha et al. (2017a). In this study, fermentation was carried out in 201 pilot plant bioreactor system integrated with firststage MF unit and second-stage NF unit. The concept of reverse MBR (rMBR) where cells are immobilized between immersed membrane layers and separated from actual substrate solution is recently introduced by Ishola et al. (2015b). Cells are encapsulated between synthetic membrane layers in the form of compact multilayer membrane column or IPC flat sheet membrane (Doyen et al. 2010). Such kind of advanced IPC rMBR configuration was used for bioethanol production from wheat straw hydrolyzate using recombinant yeast (Ishola et al. 2015b). Improved simultaneous utilization of xylose and glucose with in situ detoxification of inhibitory components was facilitated by such novel configuration.

\subsection{Membrane processes for pretreatment and concentrating substrate solution}

All existing studies of lignocellulosic bioethanol production suffer from low concentration of fermentable sugars and hence production of low concentration of ethanol, which may lead to high operational cost and energy consumption during subsequent purification stages. The conventional methods implemented for concentrating sugar solutions or detoxification include solvent extraction, evaporation, activated charcoal adsorption, and ion exchange procedures (Wei et al. 2014). High processing costs, generating additional waste materials, requirement of long processing time (Wei et al. 2014), and chances of losing sugars are the major disadvantages associated with such conventional processes (Parawira and Tekere 2011). Membrane-based selective separation systems can solve 
these issues while removing the inhibitors. To enhance the effectiveness of fermentation process and to achieve concentrated bioethanol, sugar solutions after saccharification process can be preconcentrated using suitable membranes, specifically NF membranes before fermentation. At the same time, the NF membrane scheme will be useful in the continuous separation of products during fermentation and helps to avoid product inhibition problem.

Similarly, membrane separations are also useful during the initial stages of pretreatment. Pentose and hexose sugars are mainly the endproducts after saccharification processes and there are certain microorganism that can ferment separately or both hexose and pentose sugars. As a result, separations of such hexose and/or pentose sugars sometimes become necessary during pretreatment process to accelerate fermentation efficiencies. In such cases, NF-based membrane separations have been successfully implemented for the separation of xylose from glucose before fermentation (Sjöman et al. 2007, Roli et al. 2017). Sometimes, side products such as furfural, which is toxic to fermentative microorganisms, are generated during various pretreatment processes. To achieve the maximum productivity of lignocellulosic bioethanol, it is necessary to remove such toxic materials before fermentations. The separation of toxic materials from fermentation broth through pervaporation membranes was highlighted by some researchers. Similar experiments were conducted by Ghosh et al. $(2010,2007)$ for the separation of furfural material from its mixture at different concentrations and at different temperatures through casted flat-sheet pervaporation membranes. The separation of toxic components such as phenols and furfural from biomass hydrolyzates via pervaporation mechanism was also studied by Sagehashi et al. (2007). Experiments were conducted with varying the thickness (40-200 $\mu \mathrm{m})$ of silicone rubber pervaporation membrane. It was found that keeping the separation factor constant for every experiment at constant $60^{\circ} \mathrm{C}$ temperature, total permeate flux was inversely proportional to the membrane thickness. In an another case study, Cai et al. (2013) implemented polydimethylsiloxane (PDMS) made pervaporation membrane for the removal of furfural, which originated from diluted acetic acid pretreated sweet sorghum bagasse hydrolyzate. The process was quite effective to bring down the furfural concentration from 10 to $0.6 \mathrm{~g} / \mathrm{l}$.

\subsection{Advanced membrane separation processes for recovery of bioethanol}

There are some specific membranes separation processes that have been extensively studied in the area of bioethanol separation from fermentation broth in the most purified form and made their way into commercialization successfully. In typical lignocellulosic bioethanol production process, most of the fermentative microorganisms can withstand bioethanol concentrations up to $10 \mathrm{wt} \%$. To overcome this limitation, the continuous removal of the bioethanol from fermentation broth became essential. To make the overall process energy saving and cost effective, it also necessary that produced bioethanol must be concentrated before the next refining process (Wei et al. 2014). Distillation is considered as a conventional method for the removal of ethanol from fermentation broth in concentrated form. But unluckily, the overall prospect of the process did not become attractive, as the energy requirement for the recovery of low concentration product is comparatively higher and it became difficult to directly integrate such process with fermentation because the operational temperature is much more higher (Wei et al. 2014). Therefore, such disadvantages associated with conventional distillation process lead to the selection of membrane-based advanced processes for the direct recovery of bioethanol from fermentation broth. Among these advanced processes, membrane distillation, membrane pervaporation, and membrane extractions have been extensively studied and some of them made their way into commercialization. Based on the difference of partial pressure of ethanol and water, ethanol vapor get separated through membrane distillation, whereas concentration difference between feed and permeate causes the main driving force for mass transfer in pervaporation and membrane extraction (Abels et al. 2013). In membrane extraction, two immiscible liquids are allowed to contact with each other in close vicinity of the membrane and low concentrated solutes are allowed to transfer through the membrane surface. Additional resistance of the membrane is considered as the limitation of the membrane extraction process (Abels et al. 2013). On the other side, phase change is required for membrane pervaporation mechanism to transfer the feed at the permeate side in the form of vapor phase. Mass transfer through this membrane process is not regarded as pressure driven and it can be explained with the solution-diffusion model (Wijmans and Baker 1995). Membrane pervaporation process is considered advantageous, as it allows the separation of even very low concentration of ethanol from aqueous solution. It can be implemented successfully in conventional process design, as it can minimize energy consumption of thermal unit operation such as distillation or dephlegmation.

Membrane distillation is already a well-developed process to separate bioethanol from fermentation broth. 
It is basically a thermally driven process where porous hydrophobic membrane supports water vapor transport to separate it. Such membrane-based process requires latent heat of evaporation to reach vapor-liquid equilibrium for separation and phase change from liquid to vapor. Temperature difference across the membrane comes up with vapor pressure gradient, which mainly acts as the driving force. Membrane distillation can be carried out at much lower temperature than conventional thermal distillation, as the driving force for membrane distillation does not involve directly thermal sources (Onsekizoglu 2012). So far, research focuses have been mainly made toward the identification of suitable membrane material for membrane distillation and selecting ideal process configurations. Polymeric membranes are the most preferred membranes rather than inorganic membranes for such process and have gained much more attention due to their possibility to modulate the intrinsic properties (Onsekizoglu 2012). Due to low surface tension values, polymeric membranes such as polytetrafluoroethylene, polypropylene (PP), and polyvinylidenefluoride (PVDF) are most commonly used for such process. Among different modules, plate and frame, spiral wound, tubular, capillary, and hollow-fiber membrane modules are usually implemented by different researchers (Onsekizoglu 2012). Ethanol productivity can be improved when membrane distillation operation for ethanol recovery can be coupled with fermentation process to remove the product in the form of inhibitor. Gryta et al. (2000) initially introduced the concept of direct contact membrane distillation (DCMD) for ethanol synthesis from lactose solution inside a Biotron reactor. The efficiency of ethanol production was improved through such DCMD, as it allows the selective removal of fermentation products from the reactor. Considering the partial pressure of ethanol, which is higher than the water, ethanol vapor can get transferred preferentially through the membrane pores. Membrane distillation is also considered as a sustainable alternative green technology approach because the conventional distillation technique to separate ethanol from water requires high temperature, electricity, and labor. It was reported that ethanol production can be increased by $15.5 \%$ while adopting continuous process, lowering the osmotic pressure in the fermentation broth, decreasing glycerol synthesis level, and increasing yeast cell concentration in fermentation broth (Lewandowicz et al. 2011). Membrane swelling can lead to increasing feed solution temperature, which finally helps in achieving increased membrane flux (Lewandowicz et al. 2011). It was found that the temperature of the feed has a large influence on the overall separation process. There are lots of experimental observations
(Gostoli and Sarti 1989, Udriot et al. 1989, Tomaszewska and Białończyk 2013) where distillation is directly integrated with fermentation for better separation of ethanol. Among them, Udriot et al. (1989) achieved a remarkable $87 \%$ increase in ethanol productivity in such integrated system.

Similarly, just like membrane distillation, membrane pervaporation is another well-established strategy for the separation of alcohol from fermentation broth. The process consists of two stages. Solution is being permeated through the membrane and evaporated to vapor phase through the nonporous membrane. During the process, the upstream side of the membrane will be under ambient pressure, whereas the downstream side will be under vacuum pressure. Partial pressure difference of the components on the two sides plays the most important driving force for the process and solution-diffusion is the main mechanism involved in the process. Pervaporation membrane performance is dependent on the characteristics of the membrane such as membrane thickness and the characteristics of the feed solution such as feed solution temperature and ethanol concentration in the feed (Hui et al. 2012). A specific limitation of this process is that the process is susceptible to temperature-sensitive components such as microorganisms and requires hightemperature heat source and additional heat exchanger to recover the heat (Vane 2004). Based on the characteristics and limitations of the process, research investigations have been made for the selection of a suitable membrane, development of a long-lasting process, and better process integration. Based on the material used in the pervaporation process, pervaporation membranes are classified into two groups: hydrophobic and hydrophilic. Compared to hydrophobic membranes, hydrophilic membranes are effective enough to separate water from high concentration of alcohol (>85\%; Abels et al. 2013). Due to superior temperature and mechanical stability, inorganic membranes gained lot of commercial attention. Recently, large numbers of polymeric membranes such as cellulose acetate butyrate membrane, PDMS, or polyimide (PI) membranes are commonly used for the pervaporation process. To deal with the pervaporation process with concentrated alcohol concentrations, zeolite-based membranes and/or polymeric composite membranes with polyvinyl alcohol or PI active layer can be implemented (Abels et al. 2013). It was found out that polystyrene (PS) is more hydrophobic than PDMS and also has a higher tensile and mechanical strength property, whereas some modified PDMS-PS membrane showed improved tensile and mechanical strength (Liang and Ruckenstein 1996). Huang et al. (2013) developed hydrophilic cellulose-ester 
pervaporation membrane coated with hydrophilic perfluoropolymer for high selectivity of water. Initially, water flux for water/ethanol mixture through cellulose-ester hydrophilic membrane was totally dependent on feed composition, and membrane performance was highly affected by swelling due to absorbed water. Pervaporation is a well-established process in the last three decades (Abels et al. 2013) and is available for commercial applications including a number of industrial processes. The biggest advantage of the process is its long-term stability, which has been reflected in different research investigations. Qureshi et al. (2001) investigated the performance of silicalite-silicone mixed-matrix pervaporation membrane when it was exposed to fermentation broth for $870 \mathrm{~h}$. The integrated process was successful during 10 successive fermentations runs with continuous recycle from pervaporation unit. A similar long-term applicability of newly synthesized silicon rubber-coated pervaporation membrane was studied by Ikegami et al. (2003) for $40 \mathrm{~h}$ of continuous run. Another study (Nomura et al. 2002) related to the recovery of ethanol from fermentation broth by pervaporation membrane observed a linear increase of permeate flux with increasing feed concentration of ethanol. Long time operations of more than $48 \mathrm{~h}$ were useful to achieve ethanol concentration up to $80 \%$, but it leads a significant decrease of permeate flux. In the same direction, Mulder and Smolders (1986) already suggested the suitability of pervaporation membrane for continuous long time recovery of bioethanol from fermentation broth. Dense polymeric silicon rubber membranes were used in this study for the separation of ethanol, i-propanol, and n-propanol from aqueous fermentation broth. To determine the effect of raw material and its pretreatment methods in the separation of bioethanol from fermentation broth through pervaporation, Gaykawad et al. (2013) conducted studies with different lignocellulosic substrates such as barley straw and wood chips. The raw materials were pretreated with varying concentrations of $\mathrm{H}_{2} \mathrm{SO}_{4}$. The maximum concentration of bioethanol achieved was $30 \mathrm{~g} / \mathrm{l}$ after pervaporation operations, which were conducted with commercial PDMS membrane. The economic feasibility of pervaporation operations in commercial-level ethanol production plant was established by O'Brien et al. (2004). The concentrated ethanol concentration achieved was $150-170 \mathrm{~g} / \mathrm{l}$ after pervaporation operations, conducted with a pervaporation membrane having cross-sectional area of $0.22 \mathrm{~m}^{2}$. This process also has some specific drawbacks, as operations of such integrated processes at higher temperature could lead to fouling problem (Abels et al. 2013). In the same review, the concept of a useful membrane-integrated scheme consisting of MF or UF separation in the first stage to separate cells and pervaporation system containing both hydrophobic and hydrophilic membranes in the second stage to recover pure ethanol was represented. Hydrophobic membrane was useful to separate low concentration of ethanol from fermentation broth in the first stage, whereas hydrophilic pervaporation unit leads to maximum dehydration of ethanol. Huang and Vane (2006) presented a similar integrated strategy for energyefficient recovery of bioethanol by a coupled dephlegmation/pervaporation process. In this process, two pervaporation units were coupled with one dephlegmator to achieve final ethanol concentration up to $99 \mathrm{wt} \%$.

Among all existing separation processes, membrane extraction has also emerged as a novel and most promising technology that offers numerous advantages. In membrane extraction process, large surface area is normally provided by MF or UF membrane to bring an aqueous mixture in close vicinity to the extractant. Diffusive transportation of the product from aqueous solution into the extractant is facilitated through membrane pores. Hollow-fiber membrane modules and membranes made specifically by PVDF or PP are commonly applied in this operation (Abels et al. 2013). Separation process through membrane extraction offers better transport of the product through diffusion mechanism and stability in continuous operations due to the modularity of membrane elements (Abels et al. 2013). In an experimental investigation, Vatai and Tekič (1991) implemented artificial kidney-based permeable membrane and secoctanol solvent for the membrane extraction of bioethanol from water. The conclusions made from this study were (1) as hollow-fiber modules have a large surface area, microporous hollow-fiber membrane may provide high mass transfer rate per unit volume, and (2) limitation of conventional liquid separation processes such as flooding and loading can be easily overcome by microporous membrane-based dispersion free solvent extraction mechanism. Such membrane operations have been largely implemented in the selective removal of specific components such as propionic acid, acetic acid, lactic acid, n-hexane, acetic acid, and gibberellic acid from fermentation broth, but still now no products have been commercialized and its applicability is still limited in the bioethanol separation field (Abels et al. 2013). Extraction of ethanol from fermentation broth through this technique was studied by Chang et al. (1992). In this study, diafiltration extraction membrane module with dibutylphtalat (DBP) extractant was used in the first stage of the membrane-integrated setup and maximum productivity achieved was $20 \mathrm{~g} / \mathrm{l} \mathrm{h}$. 


\subsection{Overall analysis: membrane processes in lignocellulosic bioethanol production}

Membrane separation processes are implemented successfully in different stages of bioethanol production process. More specifically, it is implemented in concentrating sugar solution before fermentation, separation of enzymes, separation of microorganism, and finally for separation and purification of bioethanol. There are number of studies where membrane-based preconcentration experiments were conducted with xylose solutions. NF membrane separations are most commonly used at lower $\mathrm{pH}$ range of solutions and overall rejection efficiencies were achieved more than 85\% in all existing studies. Surprisingly, 99.5\% rejection efficiency was achieved in a specific NF-based preconcentration experiments where the $\mathrm{pH}$ of the solution was maintained at 10 (Qi et al. 2011). Pressure-driven reverse osmosis (RO) process was also used to concentrate the solution where $99.67 \%$ rejection efficiency was achieved (Zhou et al. 2013). Similarly, like concentrating sugar solution, separation and recovery of enzymes were specifically carried out through UF membranes by different researchers. Mostly flat-sheet membranes are used in such operations. Even for the separation of bioethanol from fermentation broth, different membrane-based processes have been prioritized. Overviews of such studies related to the separation of different compounds through membrane separations are presented in Table 3.

In spite of major advantages associated with membrane technology to facilitate different stages of bioethanol production process, there are some key issues that always influence membrane performance. Concentration polarization and membrane fouling are two major concerns that affect membrane permeate flux with time. Operational feasibility of MBR does not directly support for high solid loading saccharification process as a result of low glucose concentration obtained in permeate and it finally leads to low percentage of ethanol conversion during fermentation process. High solid loading enzymatic saccharification process for lignocellulosic biomass in large-scale MBR encounters poor mixing, high viscosity, and mass transfer limitation problems (Andrić et al. 2010). Another drawback of such high solid loading enzymatic saccharification process in MBR is membrane fouling problem with untreated lignocellulosic substrate including lignin and partially recalcitrant cellulose (Andrić et al. 2010). However, most of those difficulties related to membrane operations can be resolved by effective process

Table 3: Separation of different compounds in bioethanol production through different membrane processes.

\begin{tabular}{|c|c|c|c|}
\hline Applications & Membrane & Rejection (\%) & Reference \\
\hline \multicolumn{4}{|l|}{ Sugar concentration } \\
\hline Xylose & $\mathrm{NF}$ & 66.7 & (Murthy et al. 2005) \\
\hline Xylose separation & NF & - & (Sjöman et al. 2007) \\
\hline Glucose separation & $\mathrm{NF}$ & $58-86$ & (Saha et al. 2017a) \\
\hline Xylose & $\mathrm{NF}$ & 99.5 & (Qi et al. 2011) \\
\hline Xylose & $\mathrm{NF}$ & 86.8 & (Qi et al. 2011) \\
\hline Xylose & $\mathrm{NF}$ & 85 & (Weng et al. 2009) \\
\hline Xylose & RO & 99.67 & (Zhou et al. 2013) \\
\hline Glucose & Pervaporation & - & (Wei et al. 1995) \\
\hline \multicolumn{4}{|l|}{ Separation of microorganism } \\
\hline Microorganism & MF & 100 & (Saha et al. 2017a) \\
\hline \multicolumn{4}{|l|}{ Recovery of enzymes } \\
\hline Cellulase "Onozuka" & UF & 100 & (Tanaka et al. 1988) \\
\hline Novo A/S & UF & $69 / 99.5$ & (Sagne et al. 2009) \\
\hline Cellulase and $\beta$-glucosidase & UF & $20.1 / 41$ & (Ramos and Saddler 1994) \\
\hline ABS cellulase & UF & $>94$ & (Mores et al. 2001) \\
\hline Cellulase enzymes & UF & 100 & (Knutsen and Davis 2002) \\
\hline Cellulase and cellobiase & UF & - & (Steele et al. 2005) \\
\hline Endoglucanases and exoglucanases & UF & - & (Andrić et al. 2010) \\
\hline Cellulases & MF and UF & - & (Krishna and van den Broeke 1995) \\
\hline \multicolumn{4}{|l|}{ Recovery of alcohol } \\
\hline Alcohol from alcohol-water solution & Pervaporation & - & (Abels et al. 2013) \\
\hline Ethanol from lignocellulosic broth & Pervaporation & - & (Gaykawad et al. 2013) \\
\hline Ethanol from fermentation broth & M. Extraction & $81.4 \%$ (recovery) & (Chang et al. 1992) \\
\hline Ethanol from ethanol-water mixture & M. Distillation & - & (Gostoli and Sarti 1989) \\
\hline Ethanol from fermentation broth & M. Distillation & - & (Udriot et al. 1989) \\
\hline
\end{tabular}


configuration and design configuration of membrane. Enzyme activity loss due to concentration polarization problem can be solved through the optimization of hydrolysis reaction rate and selection of suitable dilution rate (Andrić et al. 2010). It appears that enzymatic conversion efficiency inside MBR can be improved through fed-batch feeding of cellulosic substrate with intermittent product removal (Ohlson et al. 1984). Intermittent product removal through membrane processes during saccharification and fermentation processes enables to overcome product inhibition problem. On the other side, long-term performance of membrane in fouling free conditions can be ensured by virtue of sweeping flow in flat-sheet cross-flow modular operation of membrane (Dey and Pal 2012) or through sMBR system, which facilitates such operation with less energy involvement (Ylitervo et al. 2014).

\section{Advanced SSFF strategy for lignocellulosic bioethanol production}

In our identified scheme (SSFF) of two-stage membrane-integrated bioreactor system (Figure 8), UF membrane separation process facilitates enzymatic

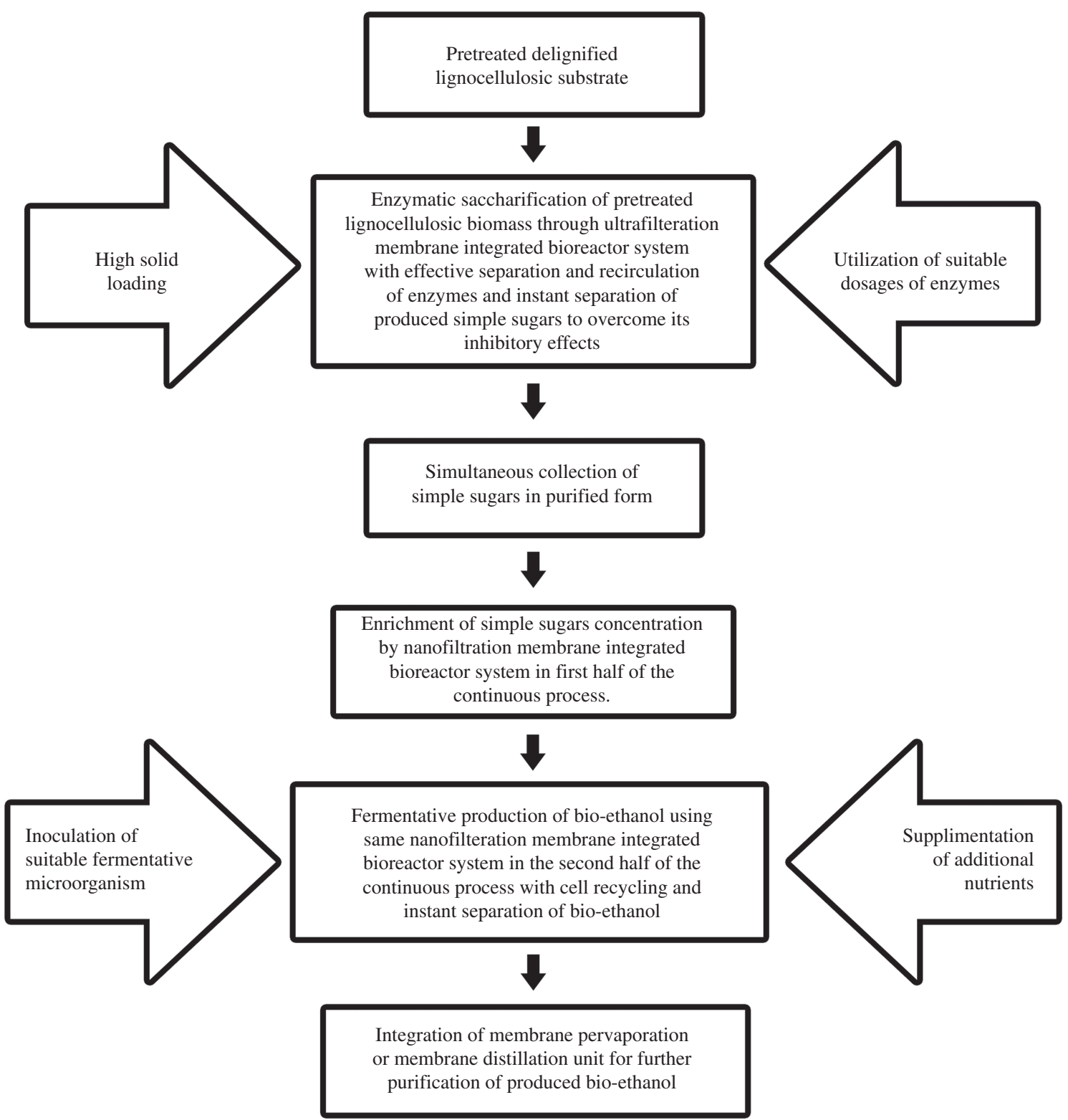

Figure 8: Schematic representation for the concept of membrane-based advanced SSFF scheme for lignocellulosic bioethanol production. 
saccharification in the first stage with efficient separation and recirculation of enzymes. The retention of enzymes in free form rather than immobilized form is implemented more (Ishola et al. 2013, 2015a,b), as the immobilized form restricts its ability to penetrate the solid substrate; hence, expected conversion efficiency will be comparatively less (Al-Zuhair et al. 2013). In the next stage of our identified membrane-integrated process, NF-based cell recycle high cell density fermentation system was proposed with prior increase of sugar concentration in bioreactor. Saha et al. (2017a) developed a similar type of two-stage membrane-integrated bioreactor system for continuous bioethanol production from sugarcane bagasse-based substrate. However, all existing studies (Ishola et al. 2013, 2015a, Ylitervo et al. 2014, Zahed et al. 2016, Saha et al. 2017a) in this research field suffer from low concentration of fermentable sugars and hence production of limited concentration of ethanol, which may lead to high operational cost and energy consumption during subsequent purification stages. To enhance the effectiveness of fermentation process and to achieve concentrated bioethanol, sugar solutions after saccharification process can be preconcentrated using suitable NF membranes before fermentation. At the same time, the NF membrane scheme will be useful for the continuous separation of products during fermentation and helps to avoid product inhibition problems. Such novel scheme of membrane-based SSFF process eliminates the disadvantages of SHF and SSF processes while allowing enzymatic saccharification and fermentation simultaneously at their separate optimum conditions. The major drawback associated with SSF process is that the fermenting organism is fully mixed with biomass and it cannot be recirculated back (Olofsson et al. 2008, Tomás-Pejó et al. 2008). Such disadvantages can be resolved by adopting membrane-based SSSF strategies. The advantages of the SSSF scheme for lignocellulosic bioethanol production were clearly highlighted by Ishola et al. (2013, 2015a,b), although specific lignocellulosic substrates such as spruce chips and wheat straw were used in those studies and MF membrane separation was used for enzyme recirculation. For the separation of enzymes that are protein in nature, UF is considered as the most suitable membrane-based operation (Wei et al. 2014). To achieve highly purified and concentrated form of bioethanol from membrane-integrated process, membrane distillation or membrane pervaporation system can be further integrated at the end of the process (Kumar et al. 2017).

\section{Status of lignocellulosic bioethanol production in the international level}

The worldwide production of bioethanol was improved from 17.25 billion liters in 2000 to more than 46 billion liters in 2007; gradually, such global production of bioethanol reached 24.5 billion gallons in 2014 (Demirbas and Balat 2006, Balat 2007). According to the dynamic international bioethanol market and government programs of major continents, total global fuel bioethanol demand is predicted to be raised beyond 125 billion liters by 2020 (Demirbas 2007). As a result for the last 20 years, governments all over the world have been actively participating in indentifying the most renewable feedstock that will be largely available throughout the year and developing sustainable technology to commercialize biofuel. Countries such as China, India, Thailand, and Japan continue to develop biorefinery manufacturing processes to produce biofuel from agricultural residues specifically from renewable lignocellulosic wastes, which ensure environmental sustainability and food security while not provoking any food crops (Limayem and Ricke 2012, Achinas and Euverink 2016). Considering the availability and low cost, most promising feedstock such as lignocellulosic wastes are considerably gaining worldwide importance. In 2010, Oulu, Finland, generated a plant to produce ethanol from various biomass, particularly from straw and bagasse under commercial cellulosic ethanol project. Currently, the world's largest cellulosic bioethanol production plant was established in Italy in October 2014, with an annual production capacity of $75,000 \mathrm{~m}^{3}$ from wheat and rice straw (Paulova et al. 2015). Queensland University of Technology (Brisbane, Australia) developed a plant to produce bioethanol from wood residues. The industrial process for the production of ethanol has been constructed by SEKAB (Sweden) from biomass including wood chips and sugarcane bagasse. The Association of British Foods and DuPont announced a $\$ 400$ million investment program for the construction of world-scale ethanol plant with an annual production capacity of 420 million liters from wheat feedstock. With the intension to facilitate sufficient cellulosic ethanol, the production of 330 million gallons of ethanol by 2012 was announced by the China Resources Alcohol Corporation. Similarly, Nippon Oil Corporation and other Japanese manufacturers, including Toyota Motors Corporation, already planned to develop a research body for the production of cellulose-derived biofuels (Menon and Rao 2012). The projected cost of bioethanol can be reduced 
from USD 1.22 per liter to about USD 0.31 per liter based on the continuous development of pretreatment of biomass, enzyme application, and fermentation process. The National Renewable Energy Laboratory (NREL; Golden, CO, USA) suggested that the ethanol production cost of 20 cents per liter can be possible in another 15 years from lignocellulosic biomass employing designer cellulases.

Few research investigations have been carried out based on membrane-based lignocellulosic bioethanol production (Han and Cheryan 1995, Gan et al. 2002, Andrić et al. 2010, Cheng et al. 2010, Al-Zuhair et al. 2013, Ishola et al. 2013, Wei et al. 2014, Ylitervo et al. 2013, 2014, Mahboubi et al. 2016) in the international level. Wei et al. (2014) presented a clear view regarding how membranebased processes can be involved in different stages of lignocellulosic bioethanol production. Mahboubi et al. (2016) also discussed the different membrane modules and substrates that were already implemented in different membrane-based bioethanol production processes. From those studies, it was concluded that mainly expensive and pure monosaccharide-based substrates and waste products got higher priority in the production of bioethanol through membrane processes. As industrial waste materials contain a high amount of heavy metals, it necessities high-quality, expensive, and time-taking purification strategies before application (Dey and Pal 2012). Wei et al. (2014) clearly explained the efficiency of NF-based selective membrane separation process for the retention of high molecular weight compounds ( $>200 \mathrm{~g} /$ mol) while permeating low molecular weight compounds (150-250 g/mol). Ylitervo et al. (2014) demonstrated that high dilution rates can be maintained for lignocellulosic bioethanol production in an sMBR system at cross-flow operating conditions. Al-Zuhair et al. (2013) developed the concept and kinetics of membrane-based enzyme recycling bioreactor system for efficient saccharification process while reusing enzymes. Among all studies, Ishola et al. (2013, 2015a) only developed the concept of membrane-based SSFF process for lignocellulosic bioethanol production.

\section{Status of lignocellulosic bioethanol production in India}

In the last decade, governments all over the world including India have been keen about identifying, developing, and commercializing technology to build up sustainable and most successful biofuel production process. The
Planning Commission released a report on April 2003, as India further strengthened its bioethanol program by analyzing and blending of various resources, price, and feedstock. As a separate ministry, the Ministry of Petroleum and Natural Gas of the Government of India authorized 5\% ethanol blend in gasoline by all oil marketing companies (Jahnavi et al. 2017). According to the Planning Commission report released in July 2003, India was encouraged to move gradually toward the dependency and use of biofuels (Bandyopadhyay 2015). The Centre for Biofuels (CBF), an establishment under the Council of Scientific and Industrial Research, is developing the key phase of a research project to develop technology to produce bioethanol as an alternative fuel for transportation. Among the biomass residues that can be preferably used as substrate, $80 \%$ can be generated mostly from crops [survey conducted by IMRB, employed by National Institute for Interdisciplinary Science and Technology (NIIST; Jahnavi et al. 2017)]. A pilot plant, the first public sector initiative in India, has been installed on the NIIST campus to produce ethanol from biomass. Ashok Pandey, Head of the CBF, has already highlighted a multifeedstock plant that will be designed to use rice and wheat straw, sugarcane, and cassava bagasse as well as bamboo and cotton waste to produce ethanol. Based on a survey covering several thousand farmers, the NIIST has highlighted the surplus biomass resources available in different parts of the country to produce bioethanol (Jenkins et al. 1998). According to the objectives of the Indian Government, Swachh Bharat Abhiyan, Department of Biotechnology, Ministry of Science and Technology-supported DBT-Institute of Chemical Technology (ICT) Center for Energy (Mumbai), has successfully demonstrated commercial lignocellulosic bioethanol production for the first time (Jahnavi et al. 2017). India Glycols Ltd. (Kashipur, Uttarakhand) was established as India's first cellulosic ethanol production plant with a production capacity of 10 t/day. The plant was successfully operated with various lignocellulosic feedstock such as wheat straw, rice straw, bagasse, cotton stalk, and bamboo and has a potential to convert those lignocellulosic residues into ethanol in less than $24 \mathrm{~h}$ (Jahnavi et al. 2017). The DBT-ICT Center for Energy is confident about their newly developed plant design that can convert 250 and 500 t/day biomass to 2G-Alcohol and can be sold at a competitive price (Jahnavi et al. 2017). Although there has been a massive growth in lignocellulosic bioethanol production in India, still membrane-integrated processes have been rarely investigated, more specifically in the industrial level for lignocellulosic bioethanol production. 


\section{Economic aspects of lignocellulosic bioethanol production}

For commercial feasibility and sustainability of lignocellulosic bioethanol production, the production cost for the conversion of biomass to liquid bioethanol is the main fundamental criteria and it must be lower than the current gasoline prices (Wayman and Parekh 1990, Subramanian et al. 2005). The feasibility of long-term supply of cheapest feedstock and uses of potent cellulases could make the process economically effective (Dien et al. 2006). Economic evaluation has been done by Wingren et al. (2008) for both SHF- and SSF-based bioethanol production processes using cellulase enzymes. Among both configurations, SSF-based approaches were proven to be less expensive by about $10 \%$, and the estimated ethanol production cost was $0.56-0.67 \$ / 1$. The NREL suggested that ethanol production cost of 20 cents per liter can be possible in another 15 years from lignocellulosic biomass employing designer cellulases and SSCF processes. The involvement of membrane technology in individual processing stages can further contribute to make the overall bioethanol production process economically more viable. The utilization of UF membrane reactor system in enzymatic saccharification process can improve the economics of the saccharification process by efficient separation and reutilization of enzymes. Other parameters that can significantly reduce the bioethanol production cost are plant size, continuous process operation, and development of the process while integrating it with the existing plant. He and Zhang (2011) developed a realistic mathematical model to indicate how the production cost of bioethanol decreases rapidly with plant size. It was suggested that the thermochemical biomass-to-ethanol plant should ideally build about $200 \mathrm{MW}$, and if the plant size increases to $1000 \mathrm{MW}$, it can further reduce ethanol cost from 0.33 to $0.25 € / 1$. The proposed cost reduction model was not totally realistic due to the limitation of feedstock availability. As the flexible configuration of membrane-integrated hybrid plant can increase the production rate without proportionate increase in plant size by applying space and energy intensification properties (Pal and Dey 2013), increasing plant size is not only the detrimental factor for the reduction of bioethanol production cost in such type of plant. It was projected that the cost of bioethanol can be reduced from 1.22 to about $0.31 \mathrm{USD} / 1$ based on the continuous development of pretreatment of biomass, enzyme application, and fermentation process where membrane technology can play the most significant role. In the same direction, Wooley et al. (1999) carried out further economic analysis of bioethanol and it was suggested that the projected cost will be as low as $\$ 0.20$ per liter by 2015 if enzymatic processing and biomass improvement processes are targeted to be combined. Di Luccio et al. (2002) investigated an economic feasibility of a membrane-integrated ethanol production plant where the fermentation system is directly coupled with final-stage pervaporation purification system and it finally ensures $6000 \mathrm{~m}^{3} /$ year ethanol and 10,000 t/year fructose production. Total capital investment cost was comparatively high, as it includes a maximum membrane cost of about $500 \mathrm{USD} / \mathrm{m}^{3}$ and high yield fructose extraction column cost of 410,000 USD/1. Although the membrane cost was considered high, higher internal return rate could make the project viable. As no phase change is involved in membrane-based processes, it can effectively replace energy-consuming and expensive processes that are normally used during the development of final substrate and product concentration. Therefore, to make the overall lignocellulosic bioethanol production process economically viable and industrially acceptable, membrane-integrated advanced SSFF approaches combining feedstock processing stages, enzymatic action, fermentation, and downstream processing stages will be definitely useful and encouraged.

\section{Conclusions}

Second-generation bioethanol production has been encouraged as an alternative solution to the problem raised by the growing energy crisis and environmental insecurity. Conventional routes for the production of such lignocellulosic bioethanol are considered feasible in the laboratory scale, but technical problems and cost economics involved in most of these processing stages make the overall process unfit for large-scale commercial sustainability. Therefore, there has been an emergent need to develop innovative technologies that can facilitate the large-scale production of lignocellulosic bioethanol while minimizing existing difficulties. Membrane processes exhibit a unique potential to improve each and individual processes involved in second-generation bioethanol production with reduced energy requirements and wide ranges of operational flexibility. Judicious integration of membrane processes in hybrid mode can come up with some useful strategies for the successful production and commercialization of lignocellulosic bioethanol. A novel concept of membrane-based advanced SSFF scheme consisting UF in the first stage followed by NF in the second stage or membrane distillation/pervaporation in the last 
stage, identified through this comprehensive review, can play an instrumental role to develop more realistic routes for sustainable lignocellulosic bioethanol production.

Acknowledgments: The authors are thankful for the financial support under Short Term Research Grant for the faculty members of the Karunya Institute of Technology and Sciences (deemed to be university) for carrying out the research work based on the presented topic.

\section{References}

Abels C, Carstensen F, Wessling M. Membrane processes in biorefinery applications. J Membr Sci 2013; 444: 285-317.

Achinas S, Euverink GJW. Consolidated briefing of biochemical ethanol production from lignocellulosic biomass. Electron J Biotechnol 2016; 23: 44-53.

Aditiya HB, Mahlia TMI, Chong WT, Nur H, Sebayang AH. Second generation bioethanol production: a critical review. Renew Sustain Energy Rev 2016; 66: 631-653.

Al-Zuhair S, Al-Hosany M, Zooba Y, Al-Hammadi A, Al-Kaabi S. Development of a membrane bioreactor for enzymatic hydrolysis of cellulose. Renew Energy 2013; 56: 85-89.

Alfani F, Albanesi D, Cantarella M, Scardi V, Vetromile A. Kinetics of enzymatic saccharification of cellulose in a flat-membrane reactor. Biomass 1982; 2: 245-253.

Alizadeh H, Teymouri F, Gilbert TI, Dale BE. Pretreatment of switchgrass by ammonia fiber explosion (AFEX). Appl Biochem Biotechnol 2005; 124: 1133-1142.

Alkasrawi M, Eriksson T, Börjesson J, Wingren A, Galbe M, Tjerneld F, Zacchi G. The effect of Tween-20 on simultaneous saccharification and fermentation of softwood to ethanol. Enzyme Microb Technol 2003; 33: 71-78.

Alvira P, Tomás-Pejó E, Ballesteros M, Negro MJ. Pretreatment technologies for an efficient bioethanol production process based on enzymatic hydrolysis: a review. Bioresour Technol 2010; 101: 4851-4861.

Alvira P, Ballesteros M, Negro MJ. Progress on enzymatic saccharification technologies for biofuels production. In: Biofuel technologies. Berlin/Heidelberg: Springer, 2013: 145-169.

AMTA (American Membrane Technology Association), America's Authority in Membrane Treatment, Publications/Resources, Membrane Technology Fact Sheets, 2014. https://www. amtaorg.com/publications-communications/membranetechnology-fact-sheets-summary\#.

Anasontzis GE, Zerva A, Stathopoulou PM, Haralampidis K, Diallinas G, Karagouni AD, Hatzinikolaou DG. Homologous overexpression of xylanase in Fusarium oxysporum increases ethanol productivity during consolidated bioprocessing (CBP) of lignocellulosics. J Biotechnol 2011; 152: 16-23.

Andrić P, Meyer AS, Jensen PA, Dam-Johansen K. Reactor design for minimizing product inhibition during enzymatic lignocellulose hydrolysis: I. Significance and mechanism of cellobiose and glucose inhibition on cellulolytic enzymes. Biotechnol Adv 2010; 28: 308-324.
Arora R, Behera S, Kumar S. Bioprospecting thermophilic/ thermotolerant microbes for production of lignocellulosic ethanol: a future perspective. Renew Sustain Energy Rev 2015; 51: 699-717.

Ashgar U, Nadeem M, Irfan M, Syed Q, Nelofer R, Iram M. Effect of $\mathrm{NaOH}$ on delignification of Saccharum spontaneum. Environ Prog Sustain Energy 2016; 35: 284-288.

Balat M. Global bio-fuel processing and production trends. Energy Explor Exploit 2007; 25: 195-218.

Balat M. Production of bioethanol from lignocellulosic materials via the biochemical pathway: a review. Energy Convers Manag 2011; 52: 858-875.

Balat M, Balat H. Progress in bioethanol processing. Prog Energy Combust Sci 2008; 34: 551-573.

Bandyopadhyay K. Biofuel promotion in India for transport: exploring the grey areas. Policy $\mathrm{Br}$ 2015: 1-12.

Bélafi-Bakó K, Koutinas A, Nemestóthy N, Gubicza L, Webb C. Continuous enzymatic cellulose hydrolysis in a tubular membrane bioreactor. Enzyme Microb Technol 2006; 38: 155-161.

Biofuels-Third Generation Biofuels, 2010. Available at: http:// biofuel.org.uk/third-generation-biofuels.html.

Bjerre AB, Olesen AB, Fernqvist T, Plöger A, Schmidt AS. Pretreatment of wheat straw using combined wet oxidation and alkaline hydrolysis resulting in convertible cellulose and hemicellulose. Biotechnol Bioeng 2000; 49: 568-577.

Bondesson PM, Galbe M, Zacchi G. Ethanol and biogas production after steam pretreatment of corn stover with or without the addition of sulphuric acid. Biotechnol Biofuels 2013; 6: 11.

Boussaid AL, Esteghlalian AR, Gregg DJ, Lee KH, Saddler JN. Steam pretreatment of Douglas-fir wood chips. Can conditions for optimum hemicellulose recovery still provide adequate access for efficient enzymatic hydrolysis? Appl Biochem Biotechnol 2000; 84-86: 693-705.

Brandberg T, Sanandaji N, Gustafsson L, Johan Franzén C. Continuous fermentation of undetoxified dilute acid lignocellulose hydrolysate by Saccharomyces cerevisiae ATCC 96581 using cell recirculation. Biotechnol Prog 2008; 21: 1093-1101.

Brodeur G, Yau E, Badal K, Collier J, Ramachandran KB, Ramakrishnan S. Chemical and physicochemical pretreatment of lignocellulosic biomass: a review. Enzyme Res 2011; 2011: 787532.

Cai J, Zhang L. Rapid dissolution of cellulose in LiOH/urea and $\mathrm{NaOH} /$ urea aqueous solutions. Macromol Biosci 2005; 5: 539-548.

Cai D, Zhang T, Zheng J, Chang Z, Wang Z, Qin P, Tan T. Biobutanol from sweet sorghum bagasse hydrolysate by a hybrid pervaporation process. Bioresour Technol 2013; 145: 97-102.

Canam T, Town JR, Tsang A, McAllister TA, Dumonceaux TJ. Biological pretreatment with a cellobiose dehydrogenase-deficient strain of Trametes versicolor enhances the biofuel potential of canola straw. Bioresour Technol 2011; 102: 10020-10027.

Cardona CA, Sánchez ÓJ. Fuel ethanol production: process design trends and integration opportunities. Bioresour Technol 2007; 98: 2415-2457.

Cardona Alzate CA, Sánchez Toro 0J. Energy consumption analysis of integrated flowsheets for production of fuel ethanol from lignocellulosic biomass. Energy 2006; 31: 2447-2459. 
Carstensen F, Apel A, Wessling M. In situ product recovery: submerged membranes vs. external loop membranes. J Membr Sci 2012; 394-395: 1-36.

Chandel AK, Singh OV, Narasu ML, Rao LV. Bioconversion of Saccharum spontaneum (wild sugarcane) hemicellulosic hydrolysate into ethanol by mono and co-cultures of Pichia stipitis NCIM3498 and thermotolerant Saccharomyces cerevisiae-VS3. N Biotechnol 2011; 28: 593-599.

Chang HN, Yang JW, Park YS, Kim DJ, Han KC. Extractive ethanol production in a membrane cell recycle bioreactor. J Biotechnol 1992; 24: 329-343.

Chapman PD, Oliveira T, Livingston AG, Li K. Membranes for the dehydration of solvents by pervaporation. J Membr Sci 2008; 318: 5-37.

Chaudhary G, Singh LK, Ghosh S. Alkaline pretreatment methods followed by acid hydrolysis of Saccharum spontaneum for bioethanol production. Bioresour Technol 2012; 124: 111-118.

Chen M, Zhao J, Xia L. Enzymatic hydrolysis of maize straw polysaccharides for the production of reducing sugars. Carbohydr Polym 2008; 71: 411-415.

Cheng LH, Yen SY, Su LS, Chen J. Study on membrane reactors for biodiesel production by phase behaviors of canola oil methanolysis in batch reactors. Bioresour Technol 2010; 101: 6663-6668.

Cheryan M, Mehaia MA. A high-performance membrane bioreactor for continuous fermentation of lactose to ethanol. Biotechnol Lett 1983; 5: 519-524.

Cotana F, Cavalaglio G, Gelosia M, Coccia V, Petrozzi A, Ingles D, Pompili E. A comparison between SHF and SSSF processes from cardoon for ethanol production. Ind Crops Prod 2015; 69: 424-432.

Dadi AP, Varanasi S, Schall CA. Enhancement of cellulose saccharification kinetics using an ionic liquid pretreatment step. Biotechnol Bioeng 2006; 95: 904-910.

Dahnum D, Tasum SO, Triwahyuni E, Nurdin M, Abimanyu H. Comparison of SHF and SSF processes using enzyme and dry yeast for optimization of bioethanol production from empty fruit bunch. Energy Procedia 2015; 68: 107-116.

Das Neves MA, Kimura T, Shimizu N, Nakajima M. State of the art and future trends of bioethanol production. Dynamic biochemistry, process biotechnology and molecular biology. Global Science Books 2007; 1: 1-14.

Demirbas A. Producing and using bioethanol as an automotive fuel. Energy Sources Pt B Econ Plan Policy 2007; 2: 391-401.

Demirbas MFF, Balat M. Recent advances on the production and utilization trends of bio-fuels: a global perspective. Energy Convers Manag 2006; 47: 2371-2381.

Den Haan R, Van Rensburg E, Rose SH, Görgens JF, van Zyl WH. Progress and challenges in the engineering of non-cellulolytic microorganisms for consolidated bioprocessing. Curr Opin Biotechnol 2015; 33: 32-38.

Dey P, Pal P. Direct production of $\mathrm{L}(+)$ lactic acid in a continuous and fully membrane-integrated hybrid reactor system under non-neutralizing conditions. J Membr Sci 2012; 389: 355-362.

Dey P, Pal P. Modelling and simulation of continuous L(+) lactic acid production from sugarcane juice in membrane integrated hybrid-reactor system. Biochem Eng J 2013; 79: 15-24.

Dey P, Linnanen L, Pal P. Separation of lactic acid from fermentation broth by cross flow nanofiltration: membrane characterization and transport modelling. Desalination 2012; 288: 47-57.
Di Luccio M, Borges CP, Alves TL. Economic analysis of ethanol and fructose production by selective fermentation coupled to pervaporation: effect of membrane costs on process economics. Desalination 2002; 147: 161-166.

Dien BS, Jung HJG, Vogel KP, Casler MD, Lamb JFS, Iten L, Mitchell RB, Sarath G. Chemical composition and response to dilute-acid pretreatment and enzymatic saccharification of alfalfa, reed canarygrass, and switchgrass. Biomass Bioenergy 2006; 30: 880-891.

Digman MF, Shinners KJ, Casler MD, Dien BS, Hatfield RD, Jung HJG, Muck RE, Weimer PJ. Optimizing on-farm pretreatment of perennial grasses for fuel ethanol production. Bioresour Technol 2010; 101: 5305-5314.

Ding W, Xiao Z, Tang X, Deng K, Fu S, Jiang Y, Yuan L. Evolutionary engineering of yeast for closed-circulating ethanol fermentation in PDMS membrane bioreactor. Biochem Eng J 2012; 60: 56-61.

Doelle MB, Millichip RJ, Doelle HW. Production of ethanol from corn using inoculum cascading of Zymomonas mobilis. Process Biochem 1989; 24: 137-140.

Doyen W, Mues W, Molenberghs B, Cobben B. Spacer fabric supported flat-sheet membranes: a new era of flat-sheet membrane technology. Desalination 2010; 250: 1078-1082.

Duarte CL, Ribeiro MA, Oikawa H, Mori MN, Napolitano CM, Galvão CA. Electron beam combined with hydrothermal treatment for enhancing the enzymatic convertibility of sugarcane bagasse. Radiat Phys Chem 2012; 81: 1008-1011.

Eggeman T, Elander RT. Process and economic analysis of pretreatment technologies. Bioresour Technol 2005; 96: 2019-2025.

Envitech C. Industrial Applications of Membrane Filtration, 2013. Available at: https://blog-en.condorchem.com/industrialapplications-of-membrane-filtration/\#.WyvyhlUza1s.

Eriksson T, Börjesson J, Tjerneld F. Mechanism of surfactant effect in enzymatic hydrolysis of lignocellulose. Enzyme Microb Technol 2002; 31: 353-364.

Ferreira S, Duarte AP, Ribeiro MHL, Queiroz JA, Domingues FC. Response surface optimization of enzymatic hydrolysis of Cistus ladanifer and Cytisus striatus for bioethanol production. Biochem Eng J 2009; 45: 192-200.

Floudas D, Binder M, Riley R, Barry K, Blanchette RA, Henrissat B, Martínez AT, Otillar R, Spatafora JW, Yadav JS, Aerts A, Benoit I, Boyd A, Carlson A, Copeland A, Coutinho PM, de Vries RP, Ferreira P, Findley K, Foster B, Gaskell J, Glotzer D, Górecki P, Heitman J, Hesse C, Hori C, Igarashi K, Jurgens JA, Kallen N, Kersten P, Kohler A, Kües U, Kumar TKA, Kuo A, LaButti K, Larrondo LF, Lindquist E, Ling A, Lombard V, Lucas S, Lundell T, Martin R, McLaughlin DJ, Morgenstern I, Morin E, Murat C, Nagy LG, Nolan M, Ohm RA, Patyshakuliyeva A, Rokas A, Ruiz-Dueñas FJ, Sabat G, Salamov A, Samejima M, Schmutz J, Slot JC, St John F, Stenlid J, Sun H, Sun S, Syed K, Tsang A, Wiebenga A, Young D, Pisabarro A, Eastwood DC, Martin F, Cullen D, Grigoriev IV, Hibbett DS. The Paleozoic origin of enzymatic lignin decomposition reconstructed from 31 fungal genomes. Science 2012; 336: 1715-1719.

Gan Q, Allen S, Taylor G. Design and operation of an integrated membrane reactor for enzymatic cellulose hydrolysis. Biochem Eng J 2002; 12: 223-229.

Gao Y, Xu J, Yuan Z, Zhang Y, Liu Y, Liang C. Optimization of fed-batch enzymatic hydrolysis from alkali-pretreated sugarcane bagasse 
for high-concentration sugar production. Bioresour Technol 2014; 167: 41-45.

Gaykawad SS, Zha Y, Punt PJ, van Groenestijn JW, van der Wielen LAM, Straath of AJJ. Pervaporation of ethanol from lignocellulosic fermentation broth. Bioresour Technol 2013; 129: 469-476.

Ghose TK. Continuous enzymatic saccharification of cellulose with culture filtrates of Trichoderma viride QM 6a. Biotechnol Bioeng 1969; 11: 239-261.

Ghose TK, Kostick JA. A model for continuous enzymatic saccharification of cellulose with simultaneous removal of glucose syrup. Biotechnol Bioeng 1970; 12: 921-946.

Ghosh UK, Pradhan NC, Adhikari B. Separation of furfural from aqueous solution by pervaporation using HTPB-based hydrophobic polyurethaneurea membranes. Desalination 2007; 208: 146-158.

Ghosh UK, Pradhan NC, Adhikari B. Pervaporative separation of furfural from aqueous solution using modified polyurethaneurea membrane. Desalination 2010; 252: 1-7.

Gonçalves FA, Ruiz HA, Nogueira C da C, Santos ES dos, Teixeira JA, Macedo GR de. Comparison of delignified coconuts waste and cactus for fuel-ethanol production by the simultaneous and semi-simultaneous saccharification and fermentation strategies. Fuel 2014; 131: 66-76.

Gonçalves FA, Ruiz HA, Silvino dos Santos E, Teixeira JA, de Macedo GR. Bioethanol production by Saccharomyces cerevisiae, Pichia stipitis and Zymomonas mobilis from delignified coconut fibre mature and lignin extraction according to biorefinery concept. Renew Energy 2016; 94: 353-365.

Gostoli C, Sarti GC. Separation of liquid mixtures by membrane distillation. J Membr Sci 1989; 41: 211-224.

Gryta M, Morawski AW, Tomaszewska M. Ethanol production in membrane distillation bioreactor. Catal Today 2000; 56: 159-165.

Hai F, Yamamoto K, Lee CH. Membrane biological reactors: theory, modeling, design, management and applications to wastewater reuse. IWA Publishing, Vol. 12, 2013: 504.

Hamelinck CN, Hooijdonk G, Faaij AP. Ethanol from lignocellulosic biomass: techno-economic performance in short-, middle- and long-term. Biomass Bioenergy 2005; 28: 384-410.

Han IS, Cheryan M. Nanofiltration of model acetate solutions. J Membr Sci 1995; 107: 107-113.

Harun S, Balan V, Takriff MS, Hassan O, Jahim J, Dale BE. Performance of AFEX ${ }^{\mathrm{TM}}$ pretreated rice straw as source of fermentable sugars: the influence of particle size. Biotechnol Biofuels 2013; 6: 40.

Hasunuma T, Kondo A. Consolidated bioprocessing and simultaneous saccharification and fermentation of lignocellulose to ethanol with thermotolerant yeast strains. Process Biochem 2012; 47: 1287-1294.

Hasunuma T, Okazaki F, Okai N, Hara KY, Ishii J, Kondo A. A review of enzymes and microbes for lignocellulosic biorefinery and the possibility of their application to consolidated bioprocessing technology. Bioresour Technol 2013; 135: 513-522.

Hatakka Al. Pretreatment of wheat straw by white-rot fungi for enzymic saccharification of cellulose. Eur J Appl Microbiol Biotechnol 1983; 18: 350-357.

Hayes DJ. An examination of biorefining processes, catalysts and challenges. Catal Today 2009; 145: 138-151.
He J, Zhang W. Techno-economic evaluation of thermo-chemical biomass-to-ethanol. Appl Energy 2011; 88: 1224-1232.

Hendriks ATWM, Zeeman G. Pretreatments to enhance the digestibility of lignocellulosic biomass. Bioresour Technol 2009; 100: 10-18.

Henley RG, Yang RYK, Greenfield PF. Enzymatic saccharification of cellulose in membrane reactors. Enzyme Microb Technol 1980; 2: 206-208.

Hernández E, García A, López M, Puls J, Parajó JC, Martín C. Dilute sulphuric acid pretreatment and enzymatic hydrolysis of Moringa oleifera empty pods. Ind Crops Prod 2013; 44: 227-231.

Himmel ME, Ding SY, Johnson DK, Adney WS, Nimlos MR, Brady JW, Foust TD. Biomass recalcitrance: engineering plants and enzymes for biofuels production. Science 2007; 315: 804-807.

Hodge DB, Karim MN, Schell DJ, McMillan JD. Model-based fed-batch for high-solids enzymatic cellulose hydrolysis. Appl Biochem Biotechnol 2009; 152: 88-107.

Hoffmann H, Kuhlmann W, Meyer HD, Schügerl K. High productivity ethanol fermentations with crossflow membrane separation techniques for continuous cell recycling. J Membr Sci 1985; 22: 235-243.

Hong J, Wang Y, Kumagai H, Tamaki H. Construction of thermotolerant yeast expressing thermostable cellulase genes. J Biotechnol 2007; 130: 114-123.

Horn SJ, Nguyen QD, Westereng B, Nilsen PJ, Eijsink VGH. Screening of steam explosion conditions for glucose production from non-impregnated wheat straw. Biomass Bioenergy 2011; 35: 4879-4886.

Huang J, Chen D, Wei Y, Wang Q, Li Z, Chen Y, Huang R. Direct ethanol production from lignocellulosic sugars and sugarcane bagasse by a recombinant Trichoderma reesei strain HJ48. Sci World J 2014; 2014: article ID 798683.

Hoyer K, Galbe M, Zacchi G. Effects of enzyme feeding strategy on ethanol yield in fed-batch simultaneous saccharification and fermentation of spruce at high dry matter. Biotechnol Biofuels 2010; 3: 14

Hui SS, Hui TH, Giam H, Sun CW, Weiye DP, Wibisono L. Membranes for Pervaporation, MT5009 Analyzing Hi-Tech Opportunities Semester 2, 2012. Available at: https://www.slideshare.net/ Funk98/membranes-for-pervaporation.

Huang Y, Baker RW, Wijmans JG. Perfluoro-coated hydrophilic membranes with improved selectivity. Ind Eng Chem Res 2013; 52: 1141-1149.

Huang Y, Vane LM. BioSep ${ }^{\mathrm{TM}}$ : a new ethanol recovery technology for small scale rural production of ethanol from biomass, United States Environmental Protection Agency (EPA), Science Inventory, Presented at 2006 National Meeting of the American Institute of Chemical Engineers, San Francisco, CA, 2006, November 12-17.

Ikegami T, Kitamoto D, Negishi H, Haraya K, Matsuda H, Nitanai Y, Koura N, Sano T, Yanagishita H. Drastic improvement of bioethanol recovery using a pervaporation separation technique employing a silicone rubber-coated silicalite membrane. J Chem Technol Biotechnol 2003; 78: 1006-1010.

Ishola MM, Jahandideh A, Haidarian B, Brandberg T, Taherzadeh MJ. Simultaneous saccharification, filtration and fermentation (SSFF): a novel method for bioethanol production from lignocellulosic biomass. Bioresour Technol 2013; 133: 68-73. 
Ishola MM, Brandberg T, Taherzadeh MJ. Simultaneous glucose and xylose utilization for improved ethanol production from lignocellulosic biomass through SSFF with encapsulated yeast. Biomass Bioenergy 2015a; 77: 192-199.

Ishola M, Ylitervo P, Taherzadeh M. Co-utilization of glucose and xylose for enhanced lignocellulosic ethanol production with reverse membrane bioreactors. Membranes (Basel) 2015b; 5: 844-856.

Jahnavi G, Prashanthi GS, Sravanthi K, Rao LV. Status of availability of lignocellulosic feed stocks in India: biotechnological strategies involved in the production of bioethanol. Renew Sustain Energy Rev 2017; 73: 798-820.

Jedvert K, Saltberg A, Lindström ME, Theliander H. Mild steam explosion and chemical pre-treatment of Norway spruce. BioResources 2012; 7: 2051-2074.

Jenkins BM, Baxter LL, Miles TR. Combustion properties of biomass. Fuel Process Technol 1998; 54: 17-46.

Judd S, Judd C. The MBR book: principles and applications of membrane bioreactors for water and wastewater treatment. Chapter 2. UK: Butterworth-Heinemann, 2011.

Kamei I, Hirota Y, Meguro S. Integrated delignification and simultaneous saccharification and fermentation of hard wood by a white-rot fungus, Phlebia sp. MG-60. Bioresour Technol 2012; 126: 137-141.

Kaseno, Kokugan T. The effect of molasses pretreatment by ceramic microfiltration membrane on ethanol fermentation. J Ferment Bioeng 1997; 83: 577-582.

Katahira S, Mizuike A, Fukuda H, Kondo A. Ethanol fermentation from lignocellulosic hydrolysate by a recombinant xylose- and cellooligosaccharide-assimilating yeast strain. Appl Microbiol Biotechnol 2006; 72: 1136-1143.

Kataria R, Ghosh S. NaOH pretreatment and enzymatic hydrolysis of Saccharum spontaneum for reducing sugars production. Energy Sources Pt A Recover Util Environ Effects 2014; 36: 1028-1035.

Kelbert M, Romaní A, Coelho E, Pereira FB, Teixeira JA, Domingues L. Lignocellulosic bioethanol production with revalorization of low-cost agroindustrial by-products as nutritional supplements. Ind Crop Prod 2015; 64: 16-24.

Kent NL, Norman L, Evers AD. Technology of cereals: an introduction for students of food science and agriculture. UK: Elsevier, 1994.

Kim S, Holtzapple MT. Lime pretreatment and enzymatic hydrolysis of corn stover. Bioresour Technol 2005; 96: 1994-2006.

Kim JW, Kim KS, Lee JS, Park SM, Cho HY, Park JC, Kim JS. Two-stage pretreatment of rice straw using aqueous ammonia and dilute acid. Bioresour Technol 2011; 102: 8992-8999.

Kim JS, Lee YY, Kim TH. A review on alkaline pretreatment technology for bioconversion of lignocellulosic biomass. Bioresour Technol 2016; 199: 42-48.

Kinoshita S, Chua JW, Kato N, Yoshida T, Taguchi H. Hydrolysis of cellulose by cellulases of Sporotrichum cellulophilum in an ultrafilter membrane reactor. Enzyme Microb Technol 1986; 8: 691-695.

Knutsen JS, Davis RH. Combined sedimentation and filtration process for cellulase recovery during hydrolysis of lignocellulosic biomass. Appl Biochem Biotechnol 2002; 98-100: 1161-1172.

Kodali B, Ravindra P. Pretreatment studies of rice bran for the effective production of cellulose. Ourense, Spain: Faculty of Science, University of Vigo at Ourense, 2006.
Krishna R, van den Broeke LJP. The Maxwell-Stefan description of mass transport across zeolite membranes. Chem Eng J Biochem Eng J 1995; 57: 155-162.

Kuhad RC, Mehta G, Gupta R, Sharma KK. Fed batch enzymatic saccharification of newspaper cellulosics improves the sugar content in the hydrolysates and eventually the ethanol fermentation by Saccharomyces cerevisiae. Biomass Bioenergy 2010; 34: 1189-1194.

Kumar P, Barrett DM, Delwiche MJ, Stroeve P. Methods for pretreatment of lignocellulosic biomass for efficient hydrolysis and biofuel production. Ind Eng Chem Res 2009; 48: 3713-3729.

Kumar S, Singh N, Prasad R. Anhydrous ethanol: a renewable source of energy. Renew Sustain Energy Rev 2010; 14: 1830-1844.

Kumar R, Ghosh AK, Pal P. Fermentative energy conversion: renewable carbon source to biofuels (ethanol) using Saccharomyces cerevisiae and downstream purification through solar driven membrane distillation and nanofiltration. Energy Convers Manag 2017; 150: 545-557.

Kuo CH, Lee CK. Enhanced enzymatic hydrolysis of sugarcane bagasse by $\mathrm{N}$-methylmorpholine- $\mathrm{N}$-oxide pretreatment. Bioresour Technol 2009; 100: 866-871.

Lee KR, Yeom IT. Evaluation of a membrane bioreactor system couple with sludge pretreatment for aerobic sludge digestion. Environ Technol 2007; 28: 723-730.

Lee WG, Park BG, Chang YK, Chang HN, Lee J, Park SC. Continuous ethanol production from concentrated wood hydrolysates in an internal membrane-filtration bioreactor. Biotechnol Prog 2000; 16: 302-304.

Leustean I. Bioethanol from lignocellulosic materials. J Agroaliment Process Technol 2009; 15: 94-101.

Lewandowicz G, Białas W, Marczewski B, Szymanowska D. Application of membrane distillation for ethanol recovery during fuel ethanol production. J Membr Sci 2011; 375: 212-219.

Li Q, Jiang X, He Y, Li L, Xian M, Yang J. Evaluation of the biocompatibile ionic liquid 1-methyl-3-methylimidazolium dimethylphosphite pretreatment of corn cob for improved saccharification. Appl Microbiol Biotechnol 2010; 87: 117-126.

Liang L, Ruckenstein E. Pervaporation of ethanol-water mixtures through polydimethylsiloxane-polystyrene interpenetrating polymer network supported membranes. J Membr Sci 1996; 114: 227-234.

Limayem A, Ricke SC. Lignocellulosic biomass for bioethanol production: current perspectives, potential issues and future prospects. Prog. Energy Combust Sci 2012; 38: 449-467.

Lin YS, Lee WC, Duan KJ, Lin YH. Ethanol production by simultaneous saccharification and fermentation in rotary drum reactor using thermotolerant Kluveromyces marxianus. Appl Energy 2013; 105: 389-394.

Lipnizki F. Membrane process opportunities and challenges in the bioethanol industry. Desalination 2010; 250: 1067-1069.

Liu Y, Xu J, Zhang Y, Yuan Z, Xie J. Optimization of high solids fed-batch saccharification of sugarcane bagasse based on system viscosity changes. J Biotechnol 2015; 211: 5-9.

Liu Y, Zhang B, Wang W, He M, Xu J, Yuan Z. Evaluation of the solvent water effect on high solids saccharification of alkali-pretreated sugarcane bagasse. Bioresour Technol 2017; 235: 12-17.

Lu Y, Wang Y, Xu G, Chu J, Zhuang Y, Zhang S. Influence of high solid concentration on enzymatic hydrolysis and fermentation of 
steam-exploded corn stover biomass. Appl Biochem Biotechnol 2010; 160: 360-369.

Lu J, Li X, Yang R, Yang L, Zhao J, Liu Y, Qu Y. Fed-batch semi-simultaneous saccharification and fermentation of reed pretreated with liquid hot water for bio-ethanol production using Saccharomyces cerevisiae. Bioresour Technol 2013; 144: 539-547.

Lynd L, Zyl W, Mcbride J, Laser M. Consolidated bioprocessing of cellulosic biomass: an update. Curr Opin Biotechnol 2005; 16: 577-583.

Mahboubi A, Ylitervo P, Doyen W, De Wever H, Taherzadeh MJ. Reverse membrane bioreactor: introduction to a new technology for biofuel production. Biotechnol Adv 2016; 34: 954-975.

Mameri N, Hamdache F, Abdi N, Belhocine D, Grib H, Lounici H, Piron D. Enzymatic saccharification of olive mill solid residue in a membrane reactor. J Membr Sci 2000; 178: 121-130.

Martín C, Galbe M, Nilvebrant NO, Jönsson LJ. Comparison of the fermentability of enzymatic hydrolyzates of sugarcane bagasse pretreated by steam explosion using different impregnating agents. Appl Biochem Biotechnol 2002; 98-100: 699-716.

Matano Y, Hasunuma T, Kondo A. Cell recycle batch fermentation of high-solid lignocellulose using a recombinant cellulasedisplaying yeast strain for high yield ethanol production in consolidated bioprocessing. Bioresour Technol 2013; 135: 403-409.

Mattila H, Kuuskeri J, Lundell T. Single-step, single-organism bioethanol production and bioconversion of lignocellulose waste materials by phlebioid fungal species. Bioresour Technol 2017; 225: 254-261.

Mehaia MA, Cheryan M. Ethanol from hydrolyzed whey permeate using Saccharomyces cerevisiae in a membrane recycle bioreactor. Bioprocess Eng 1990; 5: 57-61.

Melzoch K, Rychtera M, Markvichov NS, Pospíchalová V, Basařová G, Manakov MN. Application of a membrane recycle bioreactor for continuous ethanol production. Appl Microbiol Biotechnol 1991; 34: 469-472.

Menon V, Rao M. Trends in bioconversion of lignocellulose: biofuels, platform chemicals \& biorefinery concept. Prog Energy Combust Sci 2012; 38: 522-550.

Mesa L, Albernas Y, Morales M, Corsano G, González E. Integration of organosolv process for biomass pretreatment in a biorefinery. In: Biomass fractionation technologies for a lignocellulosic feedstock based biorefinery. Amsterdam, Netherlands: Elsevier, 2016: 229-254.

Moreno AD, Ibarra D, Alvira P, Tomás-Pejó E, Ballesteros M. A review of biological delignification and detoxification methods for lignocellulosic bioethanol production. Crit Rev Biotechnol 2015; 35: 342-354.

Mores WD, Knutsen JS, Davis RH. Cellulase recovery via membrane filtration. Appl Biochem Biotechnol 2001; 91-93: 297-309.

Mosier N, Wyman C, Dale B, Elander R, Lee YY, Holtzapple M, Ladisch $M$. Features of promising technologies for pretreatment of lignocellulosic biomass. Bioresour Technol 2005; 96: 673-686.

Mulder MH, Smolders CA. Continuous ethanol production controlled by membrane processes. Process Biochem 1986; 21: 35-39.

Murthy GS, Sridhar S, Shyam Sunder M, Shankaraiah B, Ramakrishna M. Concentration of xylose reaction liquor by nanofiltration for the production of xylitol sugar alcohol. Sep Purif Technol 2005; 44: 221-228.
Mutamim NSA, Noor ZZ, Hassan MAA, Yuniarto A, Olsson G. Membrane bioreactor: applications and limitations in treating high strength industrial wastewater. Chem Eng J 2013; 225: 109-119.

Noble RD, Giubileo G, Violante V, Fabiani C. Analysis of enzyme catalysis under batch conditions. Chem Eng J 1990; 44: B47-B50.

Nomura M, Bin T, Nakao S. Selective ethanol extraction from fermentation broth using a silicalite membrane. Sep Purif Technol 2002; 27: 59-66.

O’Brien DJ, Senske GE, Kurantz MJ, Craig JC. Ethanol recovery from corn fiber hydrolysate fermentations by pervaporation. Bioresour Technol 2004; 92: 15-19.

Ohlson I, Trägårdh G, Hahn-Hägerdal B. Enzymatic hydrolysis of sodium-hydroxide-pretreated sallow in an ultrafiltration membrane reactor. Biotechnol Bioeng 1984; 26: 647-653.

Olofsson K, Bertilsson M, Lidén G. A short review on SSF - an interesting process option for ethanol production from lignocellulosic feedstocks. Biotechnol Biofuels 2008; 1: 1-14.

Olofsson K, Palmqvist B, Lidén G. Improving simultaneous saccharification and co-fermentation of pretreated wheat straw using both enzyme and substrate feeding. Biotechnol Biofuels 2010; 3: 17.

Olson DG, McBride JE, Joe Shaw A, Lynd LR. Recent progress in consolidated bioprocessing. Curr Opin Biotechnol 2012; 23: 396-405.

Olsson L, Hahn-Hägerdal B. Fermentation of lignocellulosic hydrolysates for ethanol production. Enzyme Microb Technol 1996; 18: 312-331.

Onsekizoglu P. Membrane distillation: principle, advances, limitations and future prospects in food industry. In: Distillation - advances from modeling to applications. InTech, 2012.

Pal P, Dey P. Process intensification in lactic acid production by three stage membrane integrated hybrid reactor system. Chem Eng Process Process Intensif 2013; 64: 1-9.

Pan X, Xie D, Gilkes N, Gregg DJ, Saddler JN. Strategies to enhance the enzymatic hydrolysis of pretreated softwood with high residual lignin content. Appl Biochem Biotechnol 2005; 121-124: 1069-1079.

Pan X, Gilkes N, Saddler JN. Effect of acetyl groups on enzymatic hydrolysis of cellulosic substrates. Holzforschung 2006; 60: 398-401.

Parawira W, Tekere M. Biotechnological strategies to overcome inhibitors in lignocellulose hydrolysates for ethanol production: review. Crit Rev Biotechnol 2011; 31: 20-31.

Parisutham V, Kim TH, Lee SK. Feasibilities of consolidated bioprocessing microbes: from pretreatment to biofuel production. Bioresour Technol 2014; 161: 431-440.

Paschos T, Xiros C, Christakopoulos P. Ethanol effect on metabolic activity of the ethalogenic fungus Fusarium oxysporum. BMC Biotechnol 2015; 15: 15.

Paulova L, Patakova P, Branska B, Rychtera M, Melzoch K. Lignocellulosic ethanol: technology design and its impact on process efficiency. Biotechnol Adv 2015; 33: 1091-1107.

Pihlajaniemi V, Sipponen S, Sipponen MH, Pastinen O, Laakso S. Enzymatic saccharification of pretreated wheat straw: comparison of solids-recycling, sequential hydrolysis and batch hydrolysis. Bioresour Technol 2014; 153: 15-22. 
Prasad S, Singh A, Joshi HC. Ethanol as an alternative fuel from agricultural, industrial and urban residues. Resour Conserv Recycl 2007; 50: 1-39.

Prazeres DMF, Cabral JMS. Enzymatic membrane bioreactors and their applications. Enzyme Microb Technol 1994; 16: 738-750.

Qi B, Luo J, Chen X, Hang X, Wan Y. Separation of furfural from monosaccharides by nanofiltration. Bioresour Technol 2011; 102: 7111-7118.

Qi W, He C, Wang Q, Liu S, Yu Q, Wang W, Leksawasdi N, Wang C, Yuan Z. Carbon-based solid acid pretreatment in corncob saccharification: specific xylose production and efficient enzymatic hydrolysis. ACS Sustain Chem Eng 2018; 6: 3640-3648.

Qing Q, Yang B, Wyman CE. Xylooligomers are strong inhibitors of cellulose hydrolysis by enzymes. Bioresour Technol 2010; 101: 9624-9630.

Qureshi N, Meagher M, Huang J, Hutkins R. Acetone butanol ethanol $(A B E)$ recovery by pervaporation using silicalite-silicone composite membrane from fed-batch reactor of Clostridium acetobutylicum. J Membr Sci 2001; 187: 93-102.

Ramos LP, Saddler JN. Enzyme recycling during fed-batch hydrolysis of cellulose derived from steam-exploded Eucalyptus viminalis. Appl Biochem Biotechnol 1994; 45-46: 193-207.

Roli FM, Yussof HW, Seman MNA, Saufi SM, Mohammad AW. Separating xylose from glucose using spiral wound nanofiltration membrane: effect of cross-flow parameters on sugar rejection. IOP Conf Ser Mater Sci Eng 2017; 162: 1-6.

Saez-Miranda JC, Saliceti-Piazza L, McMillan JD. Measurement and analysis of intracellular ATP levels in metabolically engineered Zymomonas mobilis fermenting glucose and xylose mixtures. Biotechnol Prog 2006; 22: 359-368.

Sagehashi M, Nomura T, Shishido H, Sakoda A. Separation of phenols and furfural by pervaporation and reverse osmosis membranes from biomass - superheated steam pyrolysisderived aqueous solution. Bioresour Technol 2007; 98: 2018-2026.

Sagne C, Fargues C, Broyart B, Lameloise ML, Decloux M. Modeling permeation of volatile organic molecules through reverse osmosis spiral-wound membranes. J Membr Sci 2009; 330 : 40-50.

Saha BC, Iten LB, Cotta MA, Wu YV. Dilute acid pretreatment, enzymatic saccharification and fermentation of wheat straw to ethanol. Process Biochem 2005; 40: 3693-3700.

Saha K, Maharana A, Sikder J, Chakraborty S, Curcio S, Drioli E. Continuous production of bioethanol from sugarcane bagasse and downstream purification using membrane integrated bioreactor. Catal Today 2017a. https://doi.org/10.1016/j. cattod.2017.11.031.

Saha K, Maheswari UR, Sikder J, Chakraborty S, da Silva SS, dos Santos JC. Membranes as a tool to support biorefineries: applications in enzymatic hydrolysis, fermentation and dehydration for bioethanol production. Renew Sustain Energy Rev 2017b; 74: 873-890.

Saini A, Aggarwal NK, Sharma A, Yadav A. Prospects for irradiation in cellulosic ethanol production. Biotechnol Res Int 2015; 2015: article ID 157139: 1-13.

Sánchez ÓJ, Cardona CA. Trends in biotechnological production of fuel ethanol from different feedstocks. Bioresour Technol 2008; 99: 5270-5295.
Sarkar N, Ghosh SK, Bannerjee S, Aikat K. Bioethanol production from agricultural wastes: an overview. Renew Energy 2012; 37: 19-27.

Sateesh L, Rodhe AV, Naseeruddin S, Yadav KS, Prasad Y, Rao LV. Simultaneous cellulase production, saccharification and detoxification using dilute acid hydrolysate of $S$. spontaneum with Trichoderma reesei NCIM 992 and Aspergillus niger. Indian J Microbiol 2012; 52: 258-262.

Selig M. Enzymatic Saccharification of Lignocellulosic Biomass Laboratory Analytical Procedure (LAP). Issue date: 3/21/2008. Golden, CO: National Renewable Energy Laboratory, 2008.

Shahsavarani H, Hasegawa D, Yokota D, Sugiyama M, Kaneko Y, Boonchird C, Harashima S. Enhanced bio-ethanol production from cellulosic materials by semi-simultaneous saccharification and fermentation using high temperature resistant Saccharomyces cerevisiae TJ14. J Biosci Bioeng 2013; 115: 20-23.

Silverstein RA, Chen Y, Sharma-Shivappa RR, Boyette MD, Osborne J. A comparison of chemical pretreatment methods for improving saccharification of cotton stalks. Bioresour Technol 2007; 98: 3000-3011.

Singh S, Simmons BA. Ionic liquid pretreatment: mechanism, performance, and challenges. In: Wyman CE, editor. Aqueous pretreatment of plant biomass for biological and chemical conversion to fuels and chemicals. Chapter 11. Chichester, UK: John Wiley \& Sons Ltd., 2013: 223-238.

Singh LK, Majumder CB, Ghosh S. Development of sequential-coculture system (Pichia stipitis and Zymomonas mobilis) for bioethanol production from kans grass biomass. Biochem Eng J 2014; 82: 150-157.

Singh P, Suman A, Tiwari P, Arya N, Gaur A, Shrivastava AK. Biological pretreatment of sugarcane trash for its conversion to fermentable sugars. World J Microbiol Biotechnol 2008; 24: 667-673.

Sjöman E, Mänttäri M, Nyström M, Heikkilä H. Separation of xylose from glucose by nanofiltration from concentrated monosaccharide solutions. J Membr Sci 2007; 292: 106-115.

Soares J, Demeke MM, Van de Velde M, Foulquié-Moreno MR, Kerstens D, Sels BF, Verplaetse A, Fernandes AAR, Thevelein JM, Fernandes PMB. Fed-batch production of green coconut hydrolysates for high-gravity second-generation bioethanol fermentation with cellulosic yeast. Bioresour Technol 2017; 244: 234-242.

Steele B, Raj S, Nghiem J, Stowers M. Enzyme recovery and recycling following hydrolysis of ammonia fiber explosion-treated corn stover. Appl Biochem Biotechnol 2005; 121-124: 901-910.

Subramanian KA, Singal SK, Saxena M, Singhal S. Utilization of liquid biofuels in automotive diesel engines: an Indian perspective. Biomass Bioenergy 2005; 29: 65-72.

Sugiharto YEC, Harimawan A, Kresnowati MTAP, Purwadi R, Mariyana R, Andry Fitriana HN, Hosen HF. Enzyme feeding strategies for better fed-batch enzymatic hydrolysis of empty fruit bunch. Bioresour Technol 2016; 207: 175-179.

Suhara H, Kodama S, Kamei I, Maekawa N, Meguro S. Screening of selective lignin-degrading basidiomycetes and biological pretreatment for enzymatic hydrolysis of bamboo culms. Int Biodeter Biodegrad 2012; 75: 176-180.

Sun Y, Cheng J. Hydrolysis of lignocellulosic materials for ethanol production: a review. Bioresour Technol 2002; 83: 1-11.

Sun R, Lawther JM, Banks WB. Influence of alkaline pre-treatments on the cell wall components of wheat straw. Ind Crops Prod 1995; 4: 127-145. 
Sun S, Sun S, Cao X, Sun R. The role of pretreatment in improving the enzymatic hydrolysis of lignocellulosic materials. Bioresour Technol 2016; 199: 49-58.

Taherzadeh MJ. Chalmers tekniska högskola. Institutionen for kemisk reaktionsteknik. Ethanol from lignocellulose: physiological effects of inhibitors and fermentation strategies. Department of Chemical Reaction Engineering, Chalmers University of Technology, 1999. Doctoral thesis Nr. 1247.

Taherzadeh MJ, Karimi K. Enzymatic-based hydrolysis processes for ethanol. BioResources 2007; 2: 707-738.

Taherzadeh MJ, Karimi K. Pretreatment of lignocellulosic wastes to improve ethanol and biogas production: a review. Int J Mol Sci 2008; 9: 1621-1651.

Taherzadeh MJ, Millati R, Niklasson C. Continuous cultivation of dilute-acid hydrolysates to ethanol by immobilized Saccharomyces cerevisiae. Appl Biochem Biotechnol 2001; 95: 45-58.

Talebnia F, Karakashev D, Angelidaki I. Production of bioethanol from wheat straw: an overview on pretreatment, hydrolysis and fermentation. Bioresour Technol 2010; 101: 4744-4753.

Tan IS, Lee KT. Solid acid catalysts pretreatment and enzymatic hydrolysis of macroalgae cellulosic residue for the production of bioethanol. Carbohydr Polym 2015; 124: 311-321.

Tanaka M, Fukui M, Matsuno R. Removal of lignin and reuse of cellulases for continuous saccharification of lignocelluloses. Biotechnol Bioeng 1988; 32: 897-902.

Taylor MP, Eley KL, Martin S, Tuffin MI, Burton SG, Cowan DA. Thermophilic ethanologenesis: future prospects for secondgeneration bioethanol production. Trends Biotechnol 2009; 27: 398-405.

Teymouri F, Laureano-Perez L, Alizadeh H, Dale BE. Optimization of the ammonia fiber explosion (AFEX) treatment parameters for enzymatic hydrolysis of corn stover. Bioresour Technol 2005; 96: 2014-2018.

Thani A, Laopaiboon P, Laopaiboon L. Improvement of a continuous ethanol fermentation from sweet sorghum stem juice using a cell recycling system. J Biotechnol 2017; 251: 21-29.

Tin CSF, Mawson AJ. Ethanol production from whey in a membrane recycle bioreactor. Process Biochem 1993; 28: 217-221.

Tomás-Pejó E, Oliva JM, Ballesteros M, Olsson L. Comparison of SHF and SSF processes from steam-exploded wheat straw for ethanol production by xylose-fermenting and robust glucosefermenting Saccharomyces cerevisiae strains. Biotechnol Bioeng 2008; 100: 1122-1131.

Tomaszewska M, Białończyk L. Production of ethanol from lactose in a bioreactor integrated with membrane distillation. Desalination 2013; 323: 114-119.

Travaini R, Martín-Juárez J, Lorenzo-Hernando A, Bolado-Rodríguez S. Ozonolysis: an advantageous pretreatment for lignocellulosic biomass revisited. Bioresour Technol 2016; 199: 2-12.

Udriot H, Ampuero S, Marison IW, von Stockar U. Extractive fermentation of ethanol using membrane distillation. Biotechnol Lett 1989; 11: 509-514.

Van Dyk JS, Pletschke BI. A review of lignocellulose bioconversion using enzymatic hydrolysis and synergistic cooperation between enzymes - factors affecting enzymes, conversion and synergy. Biotechnol Adv 2012; 30: 1458-1480.

Vane LM. Options for combining pervaporation membrane systems with fermentors for efficient production of alcohols from biomass. Prepared for Presentation at AIChE Annual Meeting. November, USA, 2004, Topical Conference T4.
Available at: https://www.semanticscholar.org/paper/ Options-for-Combining-Pervaporation-Membrane-with-Vane/ ddbae12ed4de991a945b961f44dcd8c41e1a2bc4.

Vatai G, Tekič MN. Membrane-based ethanol extraction with hollow-fiber module. Sep Sci Technol 1991: 26: 1005-1011.

Wang YZ, Zhang L, Xu T, Ding K. Improving lignocellulose enzymatic saccharification in a bioreactor with an applied electric field. Ind Crops Prod 2017; 109: 404-409.

Water World. Membrane technology in production of biofuels. WaterWorld 2010 [WWW Document]. Available at: https://www. waterworld.com/articles/2010/10/membrane-technology-inbiofuels.html.

Wayman M, Parekh SR. Biotechnology of biomass conversion: fuels and chemicals from renewable resources. London, England: Prentice Hall, 1990.

Wei Z, Xingju Y, Quan Y. Ethanol fermentation coupled with complete cell recycle pervaporation system: dependence of glucose concentration. Biotechnol Technol 1995; 9: 299-304.

Wei P, Cheng LH, Zhang L, Xu XH, Chen H, Gao C. A review of membrane technology for bioethanol production. Renew Sustain Energy Rev 2014; 30: 388-400.

Weng YH, Wei HJ, Tsai TY, Chen WH, Wei TY, Hwang WS. Wang CP, Huang CP. Separation of acetic acid from xylose by nanofiltration. Sep Purif Technol 2009; 67: 95-102.

Westman JO, Franzén CJ. Current progress in high cell density yeast bioprocesses for bioethanol production. Biotechnol J 2015; 10: 1185-1195.

Wijmans JG, Baker RW. The solution-diffusion model: a review. J Membr Sci 1995; 107: 1-21.

Wingren A, Galbe M, Zacchi G. Techno-economic evaluation of producing ethanol from softwood: comparison of SSF and SHF and identification of bottlenecks. Biotechnol Prog 2008; 19: 1109-1117.

Wooley R, Ruth M, Sheehan J, Ibsen K, Majdeski H, Galvez A. Lignocellulosic biomass to ethanol process design and economics utilizing co-current dilute acid prehydrolysis and enzymatic hydrolysis current and futuristic scenarios. Technical Report, NREL, 1999.

Wyman CE, Dale BE, Elander RT, Holtzapple M, Ladisch MR, Lee YY, Mitchinson C, Saddler JN. Comparative sugar recovery and fermentation data following pretreatment of poplar wood by leading technologies. Biotechnol Prog 2009; 25: 333-339.

Xiao X, Bian J, Li MF, Xu H, Xiao B, Sun RC. Enhanced enzymatic hydrolysis of bamboo (Dendrocalamus giganteus Munro) culm by hydrothermal pretreatment. Bioresour Technol 2014; 159: 41-47.

Xu Q, Singh A, Himmel ME. Perspectives and new directions for the production of bioethanol using consolidated bioprocessing of lignocellulose. Curr Opin Biotechnol 2009; 20: 364-371.

Xu J, Wu B, Hu L, Wu Z, Xu N, Dai B, He J. Enzymatic in situ saccharification of lignocellulose in a compatible ionic liquidcellulase system. Chem Eng J 2015; 267: 163-169.

Yang S, Ding W, Chen H. Enzymatic hydrolysis of rice straw in a tubular reactor coupled with UF membrane. Process Biochem 2006; 41: 721-725.

Ylitervo P, Franzén C, Taherzadeh M. Impact of furfural on rapid ethanol production using a membrane bioreactor. Energies 2013; 6: 1604-1617.

Ylitervo P, Doyen W, Taherzadeh MJ. Fermentation of lignocellulosic hydrolyzate using a submerged membrane bioreactor at high dilution rates. Bioresour Technol 2014; 164: 64-69. 
Yu J, Zhang J, He J, Liu Z, Yu Z. Combinations of mild physical or chemical pretreatment with biological pretreatment for enzymatic hydrolysis of rice hull. Bioresour Technol 2009; 100: 903-908.

Zahed O, Jouzani GS, Abbasalizadeh S, Khodaiyan F, Tabatabaei M. Continuous co-production of ethanol and xylitol from rice straw hydrolysate in a membrane bioreactor. Folia Microbiol (Praha) 2016; 61: 179-189.

Zentay AN, Liang C, Lonkar S, Holtzapple MT. Countercurrent enzymatic saccharification of cellulosic biomass. Biomass Bioenergy 2016; 90: 122-130.

Zhang J, Lynd LR. Ethanol production from paper sludge by simultaneous saccharification and co-fermentation using recombinant xylose-fermenting microorganisms. Biotechnol Bioeng 2010; 107: 235-244.

Zhang Y, Xu JL, Zhang Y, He MC. Comparison of different pretreatment methods on sugarcane bagasse and fractal-like kinetics of enzymatic hydrolysis. Advant New Renew Energy 2013. Available at: http://en.cnki.com.cn/Article_en/ CJFDTOTAL-XNYJ201302008.htm.

Zhao Y, Wang Y, Zhu JY, Ragauskas A, Deng Y. Enhanced enzymatic hydrolysis of spruce by alkaline pretreatment at low temperature. Biotechnol Bioeng 2008; 99: 1320-1328.

Zhao H, Jones CL, Baker GA, Xia S, Olubajo O, Person VN. Regenerating cellulose from ionic liquids for an accelerated enzymatic hydrolysis. J Biotechnol 2009; 139: 47-54.

Zheng Y, Pan Z, Zhang R. Overview of biomass pretreatment for cellulosic ethanol production. Int J Agric Biol Eng 2009; 2: 51-68.

Zhou F, Wang C, Wei J. Simultaneous acetic acid separation and monosaccharide concentration by reverse osmosis. Bioresour Technol 2013; 131: 349-356.

Zhu JY, Pan XJ. Woody biomass pretreatment for cellulosic ethanol production: technology and energy consumption evaluation. Bioresour Technol 2010; 101: 4992-5002.

Zhu JY, Wang GS, Pan XJ, Gleisner R. The status of and key barriers in lignocellulosic ethanol production: a technological perspective. Int Conf Biomass Energy Technol 2008; 1: 3-5.

Zhuang X, Wang W, Yu Q, Qi W, Wang Q, Tan X, Zhou G, Yuan Z. Liquid hot water pretreatment of lignocellulosic biomass for bioethanol production accompanying with high valuable products. Bioresour Technol 2016; 199: 68-75.

\section{Bionotes}

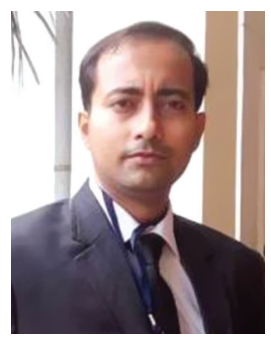

\section{Pinaki Dey}

Department of Biotechnology, Karunya University, Karunya Nagar Coimbatore 641114, India saspinaki@gmail.com

Pinaki Dey is currently working as an assistant professor at the Department of Biosciences and Technology, KITS, Coimbatore. He received his $\mathrm{PhD}$ in chemical engineering from NIT-Durgapur. He has postdoctoral experience from the Department of Biochemical Engineering, IIT, Delhi. He has been a recipient of prestigious awards such as Best Assistant Professor Award and Best Young Faculty Award. He has published several papers in the field of membrane separation, lactic acid production, PHB, and biofuel production.

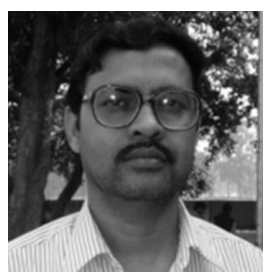

Parimal Pal

Department of Chemical Engineering, National Institute of Technology, Durgapur, India

Parimal Pal is a full-time professor at the Department of Chemical Engineering, NIT Durgapur. He has published more than 80 research papers in reputed $\mathrm{SCl}$ journals. He has already patented a lot of his developed works, produced several $\mathrm{PhD}$, and implemented many of the national and international projects under his guidance. Currently, Prof. Pal is a reviewer of about two dozens of reputed SCl journals.

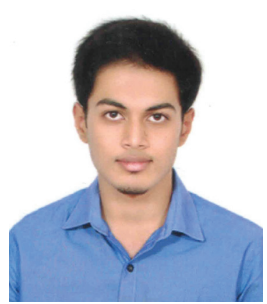

\section{Joseph Dilip Kevin}

Department of Biotechnology, Karunya Institute of Technology and Sciences, Coimbatore, India

Joseph Dilip Kevin is currently pursuing his B-Tech degree in biotechnology at the Department of Biosciences and Technology, Karunya Institute of Technology and Sciences (deemed to be University), Coimbatore, India. He is a final-year student. His research interests include biochemical engineering, molecular biology, and designing bioreactors.

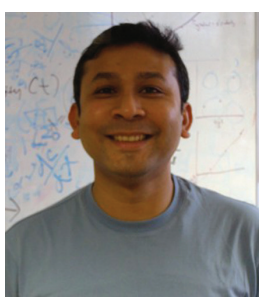

\section{Diganta Bhusan Das}

Department of Chemical Engineering, School of AACME, Loughborough University, Loughborough, Leicestershire, UK

Diganta Bhusan Das is a senior lecturer and the leader of the Process Engineering Research Theme at Loughborough University, UK. He is also the Deputy Academic Lead of the University Global Research Challenge on Changing Environment and Infrastructures and an editor of three journals (e.g. Water Science and Technology). Diganta has successfully supervised three postdoctoral and $19 \mathrm{PhD}$ students. He has published 90 refereed journal papers and five books coauthored/coedited. 